\title{
La configuración de la maquinaria sobrenatural en la poesía épica de Gabriel Lobo Lasso de la Vega*
}

\author{
The configuration of the supernatural machine \\ in the epic poetry of Gabriel Lobo Lasso de la Vega
}

\author{
Antonio Río Torres-Murciano \\ Universidad Nacional Autónoma de México \\ antonio_rio@enesmorelia.unam.mx \\ ORCID iD: https://orcid.org/0000-0001-5796-6699
}

RESUMEN: Las notables diferencias que se dan entre las dos epopeyas acerca de la conquista de México escritas por Gabriel Lobo Lasso de la Vega - la Primera parte de Cortés valeroso y Mexicana (Madrid, Pedro Madrigal, 1588) y la Mexicana (Madrid, Luis Sánchez, 1594) - son resultado del paso de un paradigma poético basado principalmente en la Araucana de Alonso de Ercilla a uno nuevo definido por la confluencia de la Jerusalén liberada de Torcuato Tasso con la Eneida de Virgilio.

Palabras clave: épica española, Gabriel Lobo Lasso de la Vega, Alonso de Ercilla, Torcuato Tasso, Virgilio, Hernán Cortés.

ABSTRACT: The striking differences between Gabriel Lobo Lasso de la Vega's two epics on the conquest of Mexico - Primera parte de Cortés valeroso y Mexicana (Madrid, Pedro Madrigal, 1588) and Mexicana (Madrid, Luis Sánchez, 1594) - are the result of passing from a poetic paradigm mainly based on Alonso de Ercilla's

\footnotetext{
* Este estudio es producto del proyecto de investigación "De la épica romana a la épica de Indias. La pervivencia de los modelos clásicos en las epopeyas sobre la conquista de México", financiado por el Consejo Nacional de Ciencia y Tecnología de México (CONACYT, CB 2014/ 241095). Agradecemos a Sandra Romano Martín, a Juan María Gómez Gómez y a Xosé Antonio López Silva que nos hayan hecho llegar sus trabajos, y muy especialmente a Betriz Fornell Puertas que haya puesto a nuestra disposición la edición del De gestis Mendi de Saa del P. José de Anchieta realizada por José María Fornell Lombardo, recientemente fallecido. Lamentamos no haber podido consultar la tesis de Avilés Pérez (1936).
} 
Araucana to a new one defined by the confluence of Torquato Tasso's Gerusalemme liberata with Vergil's Aeneid.

Keywords: Spanish epic, Gabriel Lobo Lasso de la Vega, Alonso de Ercilla, Torquato Tasso, Virgil, Hernán Cortés.

\section{INTRODUCCIÓN}

El carácter histórico de las epopeyas de Indias, vindicado en su momento como virtud por los propios autores en la idea de "la superioridad moral y ontológica de lo verdadero sobre lo fingido" (Vega, 2010: 109), hizo que en tiempos más recientes se las menospreciara como meras "crónicas rimadas"1, o bien se las considerara ejemplos de la historicidad y el verismo respectivamente atribuidos a la épica hispánica por Menéndez Pelayo (1884: 361, n. 1) y por Menéndez Pidal (1949: 124-129) 2 . Y, si la primera de estas dos actitudes contribuyó a que se fijara la atención más en las fuentes cronísticas de los poemas que en sus modelos literarios, la segunda tendió a obviar la presencia en ellos del componente sobrenatural heredado de la tradición de la épica culta. Es cierto que la materia de los Lusíadas es fundamentalmente histórica, pero sólo si se desatienden algunas de las modificaciones mediante las cuales Luis de Camões la dotó de forma épica se puede afirmar que el gran poeta portugués "desecha, con pleno conocimiento de causa, la fabulación mitológica de Homero y de Virgilio" (Menéndez Pidal, 1949: 128). Porque, tal como lo narra Camões, el viaje de Vasco de Gama a la India encuentra continuamente un correlato sobrehumano en las banderías de los dioses del Olimpo, que intervienen en los asuntos terrenos para favorecer a unos mortales o a otros de maneras muy similares a como lo hacían en Homero y en Virgilio³. Así, la materia recabada de las

\footnotetext{
1 Puede rastrearse en Quintana (1833: 8) la idea que subyace al marbete, cuya formulación parece remontarse a los respectivos juicios pronunciados por Bouterwek (1804: 410) y por Schlegel (1815: 95) acerca de Alonso de Ercilla ("ein versificirender Geschichtschreiber") y de la Araucana ("eine versifizirte Reisebeschreibung und Kriegsgeschichte"); en su versión inglesa ("rhyming chronicles"), la etiqueta fue usada por Ticknor (1864: 506) para decretar el que él consideró fracaso en España de la poesía narrativa heroica de asunto nacional. La cuestión del estatuto poético de la épica histórica es, por lo demás, tan antigua al menos como la Poética de Aristóteles, en la que, con una velada referencia a las Pérsicas de Quérilo de Samos, se niega que Heródoto puesto en verso pueda ser otra cosa que historia (1451b 1-6); v. Newman (1986: 26, 40 n. 11, 204 n. 37).

${ }^{2}$ La recurrente teoría de la persistencia transhistórica de la épica hispana en su supuesto carácter verista ha sido acertadamente criticada por Lara Garrido (1999: 27-35)

${ }^{3}$ La narración se abre en el Olimpo (1.20 y sigs.) con un concilio presidido por Júpiter en el cual se presentan las posturas antagónicas de Baco y de Venus, enemigo y protectora de los portugueses, cuyas intervenciones se suceden a lo largo del relato (1.73 y sigs., 100, 104; 2.10 y sigs.,
} 
fuentes historiográficas toma forma a la luz de unos modelos literarios determinados, que para el género épico imponían desde la Ilíada el desarrollo paralelo de la narración en dos planos: el humano y el divino ${ }^{4}$. La pujanza de esta exigencia era tal que, cuando los épicos modernos decidieron sacrificar la maquinaria divina pagana en aras de la verosimilitud cristiana - en lugar de someterla a una interpretación alegórica, como había hecho Camões ${ }^{5}$-, tendieron a concebir como sustitutos de los viejos dioses a los magos y hadas de la tradición romancesca medieval o a los ángeles y demonios del maravilloso cristiano, con cuya actividad creyeron preservar en sus obras la admiración característica del género heroico ${ }^{6}$. Se encontraba, no obstante, entre los modelos antiguos una

18 y sigs., 33 y sigs.; 6.6 y sigs., 85 y sigs.; 8.45 y sigs., 64 y sigs.; 9.18 y sigs.). En la intercesión de Venus ante Júpiter (2.33-55) y el subsiguiente despacho de Mercurio a la Tierra (2.56-64) es especialmente perceptible la imitación de la Eneida $(1.227-304 ; 4.239-244,554-580)$, mientras que la mención de la capacidad profética de Proteo (10.7), explotada en el De partu Virginis de Sannazaro (3.334 y sigs.) se remonta en última instancia a Homero (Od. 4.430 y sigs.). Junto a estos dos modelos - entre los cuales Virgilio es, sin duda, el fundamental, aun cuando la acción divina en los Lusíadas sea, como ha hecho ver Alves (2001: 208-210), menos coherente que en la Eneida - hay que conceder un lugar ciertamente destacado a las Argonáuticas de Valerio Flaco (Post, 1958), poema considerado prototipo del de Camões por Salgado (1950 y 1951), cuyos excesos reprendió Carvalho (1970). La idea de que los dioses y los hombres actúan en Camões en planos perfectamente separados, con la cual quedaría a salvo hasta cierto punto el realismo del épico portugués, ha sido acertadamente criticada por Alves (2001: 553-554, 675-676).

${ }^{4}$ Este dualismo es reconocido por el propio Homero cuando le hace afirmar a Penélope que Femio, el bardo de la corte de Ítaca, conoce "hechos de los hombres y de los dioses, que cantan

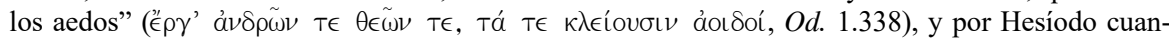
do dice "después de que el aedo, servidor de las Musas, cante los hechos de los hombres antiguos

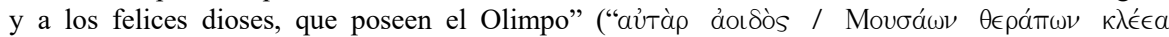
протє́р semejantes términos reza la definición griega de la poesía épica transmitida por Suetonio en su De poetis: "el epos es abarcamiento de hechos divinos y de heroicos y humanos" ("'̌t

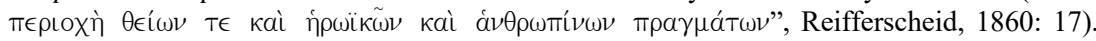

${ }^{5}$ Hacia el final de los Lusíadas se suceden, de hecho, hasta tres posibles lecturas alegóricas de la maquinaria divina. Mientras que en el canto 9 , y por boca del narrador, se yuxtapone inmediatamente la interpretación evemerista (90-92) a otra de índole moral, que equipara las ninfas que agasajan a los portugueses en la isla de Venus a las "honras que a vida fazem sublimada" (89; cf. 10.737-738), en el canto 10 se utiliza el discurso de Tetis para proponer un descifre en clave cristiana por el cual Júpiter es identificado con la divina Providencia (83) y los demás dioses con los ángeles (84) — con lo que se confirman a la postre las percepciones de Gama, que a lo largo del poema interpreta reiteradamente como intervenciones de la Providencia las que al lector le son relatadas como injerencias del teatro olímpico en los asuntos humanos (2.30-32, 65; 6.80-85) - No son, sin embargo, incompatibles entre sí las diversas alegoresis, como bien ha explicado Alves (2001: 617-642) a pesar de Bowra (1945: 118-120).

${ }^{6}$ Esta idea, sobre la cual ha llamado recientemente la atención Gregory (2006: 11), se halla expresada en las consideraciones hechas al respecto por Torcuato Tasso en el primero de sus Discorsi dell'arte poetica (1587: 3r-4r) y ampliadas en el libro 2 de sus Discorsi del poema eroico (1824: 54-61), y es la misma que expone pro domo sua Bernardo de Balbuena en el prólogo del Bernardo: "Y porque a la majestad heroica, conforme a nuestra religión, hacen falta para 
notable excepción al principio de narración en doble plano, constituida por una epopeya histórica, la Farsalia de Lucano, que renuncia expresamente a implicar a los dioses en los asuntos de los hombres ${ }^{7}$, y que, en atención al origen hispano de su autor, fue considerada por Milá y Fontanals (1844: 104) y por Menéndez Pidal (1949: 127) como hito fundacional del verismo patrio ${ }^{8}$. A Lucano han remitido reiteradamente los estudiosos la épica española en general, la épica de Indias en particular y, más concretamente, el ejemplar más celebrado de este subgénero: la Araucana de Alonso de Ercilla9. Hay que precisar, sin embargo, que, si bien toda la épica de Indias puede ser calificada de "lucanea" por cuanto trata hechos históricos más o menos recientes - aunque no por el enfoque ideológico con que lo hace ${ }^{10}$-, la Araucana puede serlo, además, por

lo verosímil las deidades y semideos con que los antiguos hacían tan admirables y pomposos sus poemas, el Boyardo y los que le han seguido inventaron en su lugar las hadas y encantamientos de los magos, que, siendo potestades superiores, sirven de levantar la fábula, y hacerla en el deleite y alegoría más vistosa y admirable" (Rosell, 1851: 141). Balbuena sigue de cerca a Alonso López Pinciano (1596: 493), si bien la sustitución de lo antiguo por lo moderno en el plano sobrenatural la trata más ampliamente Francisco Cascales (1617: 259-261).

${ }^{7}$ Las negaciones más explícitas de la supremacía de Júpiter ("mentimur regnare Iouem", 7.447) y de la implicación de dios alguno en las cosas mortales ("mortalia nulli / sunt curata deo", 7.454455) son proferidas por el narrador justo antes relatar la batalla decisiva de la guerra civil entre cesarianos y pompeyanos (7.460 y sigs.). Esta extravagante opción poética le granjeó a Lucano la crítica de Servio (ad Aen. 1.382) y antes, con ironía o sin ella, la de Petronio (Sat. 118).

${ }^{8}$ Acerca del modo y de la medida en que los literatos y estudiosos españoles han considerado desde el Renacimiento a Lucano como compatriota se encuentran interesantes reflexiones recientes en Nicolopulos (2000: 285, 285 n. 16) y en López Silva (2013: 377-378, 385-394 y 2015: 398).

${ }^{9} \mathrm{La}$ idea de que el gusto de la épica hispánica por la historia obedece a la adopción de Lucano como modelo puede rastrearse en la bibliografía desde los despectivos juicios de Bouterwek (1804: 408) y los más ponderados de Puibusque (1853: 280) y de Nicolas (1869: cxxxviii-cxxxix, cliclvi) hasta las matizadas apreciaciones de Vilà (2003: 141-144, 2006: 93 n. 18 y 2010: 4-5, 2324) y de Vega (2010: 107-108), pasando por Pierce (1961: 214). La opción de Ercilla por la materia histórica ha sido puesta en relación con la de Lucano desde Nicolás Antonio (1672: 16); v. Pierce (1961: 34).

${ }^{10}$ Bien ha hecho notar Vilà (2003: 140-141 y 2009: 9) que, al adoptar el modelo lucaneo, la épica española prescinde del desencanto antiimperial que lo caracteriza - pero que no parece haber sido plenamente percibido durante el siglo XVI (Nicolopulos, 2000: 27) - para sustituirla por un triunfalismo panegírico virgiliano que poco tiene que ver con la retórica de la "épica de los vencidos". El lucaneísmo ideológico hallado en Ercilla por Davies (1979) y por Quint (1993: 157185) resulta difícilmente sostenible a la luz de las reflexiones que McManamon (1955: 175-176, 237, 282-284), Adorno (1986: 17-19), Cevallos (1989), Lerner (1994 y 1999) y Nicolopulos (2000: 5-7) han hecho acerca de la perspectiva con que se enfoca en la Araucana la conquista, a las cuales pueden añadirse las realizadas por Davis (2000: 13-17) a propósito de la épica hispana en general y de la de tema mexicano en particular (Davis, 2002), así como la aguda observación de Janik (1969: 102) acerca de la posibilidad de que la influencia de la Farsalia haya conferido a la Araucana acentos ajenos a la intención del autor. Como ha hecho ver Kallendorf (2003), la duplicidad de las lecturas modernas, optimistas o pesimistas, del poema de Ercilla procede en todo caso de la ambigüedad virgiliana $-\mathrm{y}$ no, precisamos nosotros, de la oposición lucanea al imperio- que este incorpora. 
la ausencia del plano superior de la narración que cabría esperar en un poema épico. No hay, en efecto, en el relato de Ercilla una trama sobrenatural que se superponga a la humana e influya continuamente en esta, ya esté representada por los dioses de Virgilio y de Camões, por los hechiceros de Ariosto y de Bernardo de Balbuena o por los ángeles y demonios de Tasso. Pero este es un rasgo lucaneo que no puede extenderse al entero corpus de la épica de Indias, pues no fueron pocos los poetas que, a pesar de lo mucho que debían a la Araucana en otros aspectos, optaron por mantener en sus obras el principio épico de la narración en doble plano, explotando las posibilidades que a este respecto les ofrecían algunos de los modelos a los que nos acabamos de referir. En las páginas que siguen estudiaremos el caso del poeta madrileño Gabriel Lobo Lasso de la Vega, que resulta especialmente ilustrativo por la manera en que la confontación de su primera epopeya sobre la conquista de México - Primera parte de Cortés valeroso y Mexicana (Madrid, Pedro Madrigal, 1588) - con la segunda - Mexicana (Madrid, Luis Sánchez, 1594) - permite percibir el proceso de alteración del paradigma ercillesco.

\section{El CORTÉS VALEROSO}

\subsection{El paradigma ercillesco}

La Primera parte de Cortés valeroso y Mexicana se publicó precedida por un prólogo del autor en el cual Pierce (1961: 239) creyó encontrar "la definición de la crónica rimada". Es de notar, en efecto, el énfasis puesto por Lobo Lasso no sólo en la "verdad" de su "historia" 11 , sino también en el rigor del trabajo que dice haber llevado a cabo con las fuentes (Pullés-Linares, 2005: 131) ${ }^{12}$ :

\footnotetext{
${ }^{11}$ Idea esta que es recurrente en Ercilla — quien, tras proponerla en el prólogo ("considerando ser la historia verdadera"; Lerner, 1998: 69), la retoma en varias ocasiones a lo largo del poema (1.3.5-6; 2.60; $16.2312 .73 .1-4)$ - y que, como ya notó Nicolas (1869: cxlvii-cl) devino tópico en la épica histórica hispana. En las páginas que siguen nos referiremos a las partes primera (Madrid, Pierres Cosin, 1569) y segunda (Madrid, Pierres Cosin, 1578) de la Araucana, puesto que la tercera (Madrid, Pedro Madrigal, 1589) es posterior al Cortés valeroso.

${ }^{12} \mathrm{El}$ texto del Cortés valeroso se citará por la edición de Pullés-Linares (2005), modificando en ocasiones la ortografía y la puntuación, con remisión a número de canto, de estrofa y, en su caso, de verso para el poema, y a número de página para los preliminares y las notas. Se utilizarán de aquí en adelante las abreviaturas siguientes: Aen. (Virgilio, Eneida); Ar. (Alonso de Ercilla, Araucana, 1569-1589); CF (Luis Zapata, Carlo famoso, 1566); CV (Gabriel Lobo Lasso de la Vega, Cortés Valeroso, 1588); GL (Torcuato Tasso, Gerusalemme liberata, 1581); Il. (Homero, Ilíada); In Ruf. (Claudio Claudiano, In Rufinum); Lus. (Luis de Camões, Os Lusíadas, 1572); Met. (Ovidio, Metamorfosis); Mex. (Gabriel Lobo Lasso de la Vega, Mexicana, 1594); Od. (Homero, Odisea); OF (Ludovico Ariosto, Orlando Furioso, 1532); PV (Jacopo Sannazaro, De partu virginis, 1526); Rapt. (Claudio Claudiano, De raptu Proserpinae).
} 
Volviendo pues al propósito desta historia de Fernando Cortés, digo que, para prueba de su verdad y de cuan arrimado voy a ella en este mi pequeño discurso, remito a los lectores a sus milagrosas historias, cuyos puntos principales yo he seguido en él, inquiriendo muchos papeles curiosos con notoria verdad autorizados y relaciones que no pequeño trabajo y costa me han tenido, por los cuales he sabido muchas cosas de que lo escrito hasta aquí carece [...].

No parece, sin embargo, que se haya apartado sustancialmente de la Conquista de México de Francisco López de Gómara (Zaragoza, Agustín Millán, 1552), expresamente mencionado en el poema $(1.29 .3)^{13}$. ¿Debemos, pues, entender que estamos ante una perfecta "crónica en verso", adjudicándole al Cortés valeroso la etiqueta dada por Gaylord (2000: 73) a la Mexicana de 1594? En absoluto, a menos que pasemos por alto el intrincado juego mediante el cual se superponen a la fuente cronística los diversos modelos literarios.

El propio Lasso indica en el prólogo dos lugares de su epopeya en los cuales reconoce haber introducido "poesía y ficciones" (Pullés-Linares, 2005: 132):

Sólo en la variedad del onceno canto y descripción de la casa de la envidia del doceno podrá el lector recrear algún tanto el ánimo cansado de tantas veras y verdades, si gustare de poesia y ficciones, como en cosas que lo son, porque historia de tanta autoridad como esta ninguna mixtura della consiente sin ir muy declarada por tal.

El canto 11 constituye todo él una digresión saturada de mitológía clasica que excede, como se verá, el marchamo de "episodios fantásticos o novelescos" aplicado por Amor y Vázquez (1970: xxii) tanto a este como a las aventuras de la india Clandina, librada por Jerónimo de Aguilar de ser forzada por su pretendiente Hirtano (4.51-115) y de ser sacrificada por los bandidos que la han secuestrado junto a su esposo Hipandro (8). De hecho Amor y Vázquez, que identificó plausiblemente los pasajes de Gómara que podrían haber dado pie a estas invenciones de Lasso ${ }^{14}$, parece haber confundido dos maneras de desviarse del curso histórico de la crónica que son esencialmente distintas porque proceden de tradiciones literarias distintas, aunque interrelacionadas. Tenemos, por un lado, los dos episodios de Clandina, a los que habría que sumar aquel en el que otra india, Gualca, advierte a Pedro de Alvarado de la traición de los

\footnotetext{
${ }^{13}$ Esta filiación ha sido reconocida tanto por Pullés-Linares (2005: 38-39) en el Cortés valeroso como por Amor y Vázquez (1970: xx) en la Mexicana; extraña, por tanto, que, para ilustrar el contenido histórico de la narración, la primera recurra continuamente en sus notas a Bernal Díaz del Castillo, cuya Historia verdadera de la conquista de la Nueva España no fue conocida por Lasso.

${ }^{14}$ La busca de vituallas en Tabasco (cap. 19) y la toma de Tizapancinca (cap. 38) habrían proporcionado a Lasso las ubicaciones respectivas de los dos encuentros de Aguilar con Clandina, y el descanso de los españoles en Tlaxcala tras la guerra con los habitantes de esta ciudad (cap. 54) habría inspirado la fiesta descrita en el canto 11.
} 
cholultecas (12.16-28), aun cuando en este caso se trate de una alteración y no de un añadido al relato de Gómara ${ }^{15}$; ambas mujeres tienen en Ercilla modelos que provienen, a su vez, del Orlando furioso de Ludovico Ariosto ${ }^{16}$, pero no son estas las "ficciones" por las cuales Lasso sintió la necesidad de disculparse en el prólogo. Hay, por otro lado, un canto entero, el 11, y un episodio concreto del 12 que sí son expresamente objeto de la mencionada disculpa preliminar, y que tienen en común que introducen la maquinaria sobrenatural en un poema que hasta entonces la había desechado ${ }^{17}$.

Entre los rasgos compartidos por los diez primeros cantos del Cortés valeroso con la Araucana que podríamos llamar "lucaneos" en sentido amplio, como

15 En Gómara (cap. 59, Miralles Ostos, 1988: 90-91) es "una mujer de un principal” quien avisa a doña Marina, la cual, junto con Jerónimo de Aguilar, da parte a Cortés. Lasso se basó en un anterior pasaje de Gómara (cap. 58, Miralles Ostos, 1988: 88) en el cual una india entregada a Pedro de Alvarado en Tlaxcala le descubre a este la trampa urdida junto con los de Cholula por un hermano suyo, a quien Cortés ordena estrangular en secreto ya antes de que los españoles dejen la primera ciudad para dirigirse a la segunda.

${ }^{16}$ La conversación de Gualca con Alvarado evoca la de Guacolda con Lautaro (Ar. 13.43-57), remitida por Ducamin (1900: 106 n. 5), Chevalier (1966: 152) y Schwartz Lerner (1972: 619) a la ariostesca de Doralice con Mandricardo ( $O F$ 30.38-42); se presenta, además, precedida de un apóstrofe a las damas (12.16-18) que, como ha señalado Pullés-Linares (2005: 330 n. 42), procede igualmente de Ercilla (Ar. 19.1-2). El personaje de Clandina reescribe en parte el de Glaura (Ar. 28.6-17), cuyo parentesco con la Isabella de Ariosto (OF 12.88-13.43) ha sido notado por Ducamin (1900: 199 n. 1), Aubrun (1956: 265), Chevalier (1966: 152), Schwartz Lerner (1972: 624) y Lerner (1998: 761 n.12). En el segundo de los episodios protagonizados por Clandina la deuda de Lasso con Ariosto es, no obstante, directa, pues su heroína es, como Isabella, raptada por bandidos y encerrada en una cueva, de la que es rescatada por Aguilar como la otra lo es por Orlando; se diría incluso que la "pequeña luz" que le delata improvisadamente a Aguilar la ubicación de la gruta ( $C V$ 8.6.7) es hermana del "splendor" que en circunstancias muy similares sirve de guía a Orlando $(O F$ 12.86-89). Además, el relato de la muerte de Tádara ( $C V$ 8.41-50) parece inspirado en las Etiópicas de Heliodoro (1.30.7-1.31.1), con lo que Lasso habría recurrido en este punto - directamente o mediante alguna traducción - al que quizás fue, aun a pesar de Rajna (1900: 228 n. 4), modelo griego del episodio ariostesco de Isabella. Se halla, sin embargo, en el de Clandina un elemento que no se puede retrotraer ni a Ercilla ni a Ariosto ni a Heliodoro, como es la truculenta descripción del canibalismo de los forajidos, y esta podría proceder de un pasaje del Nuevo Mundo y Conquista de Francisco de Terrazas en el que se describen las sevicias del cacique Canebato —versión ultramarina del Polifemo de Virgilio (Río Torres-Murciano, 2016: 91-95; Romano Martín, 2017)_; la rúbrica de esta imitación la constituye un verso de Lasso ("en vino y carne humana sepultados", 8.14.8) que es, a nuestro juicio, variación de uno de Terrazas ("en vino y grave sueño sepultados", fr. 15.224, Castro Leal, 1941), a su vez muy parecido — aunque no idéntico, como creyó Wogan (1941: 372) — a uno de la Araucana ("en vino y dulce sueño sepultados", 14.6.8). Este segundo episodio de Clandina podría, por lo demás, haber influido en el Persiles de Cervantes (Schuessler, 1997).

${ }^{17}$ La expresión "poesía y ficciones" parece, pues, restringirse en el prólogo del Cortés valeroso al plano no humano, como si Lobo hubiera interpretado en sentido estrictamente quiástico al igual que hace, convincentemente, Gregory (2006: 1-3) - la definición del poema heroico dada por Servio: "est autem heroicum quod constat ex divinis humanisque personis, continens vera cum fictis" (ad Aen. 1 praef.). 
son el gusto por la digresión etnográfica ${ }^{18}$, el enaltecimiento de los vencidos ${ }^{19} \mathrm{y}$ la atribución de la inspiración poética al favor de un mortal ${ }^{20}$, destaca, en estrecha relación con este último, la ausencia de un nivel superior de la narración cuyas vicisitudes incidan de manera continuada en el desarrollo de los acontecimientos en el nivel inferior. Los dioses paganos, aunque reiteradamente mencionados en una y otra obra, son rara vez algo más que metonimias o personificaciones ${ }^{21}$, incluso en las contadas ocasiones, limitadas siempre a episodios al margen del hilo principal del relato, en que se les concede cierta capacidad de actuación ${ }^{22}$.

${ }^{18}$ No parece, desde luego, coincidencia que, como Ercilla (Ar. 1.6-46), Lasso abra su relato con una prolija descripción geográfico-etnográfica $(C V$ 1.11-30) en la cual se enfatiza el trato nefando de los indios con los demonios (Ar. 1.42; $C V$ 1.15-16). La filiación lucanea del pasaje ercillesco ha sido notada por Chevalier (1966: 145)

${ }^{19}$ Es digno de nota el sobresaliente lugar que ocupa la vindicación de la valía de los indios tanto en el prólogo de la Araucana (Lerner, 1998: 69-70) como en el del Cortés valeroso (PullésLinares, 2005: 132-133), poema en el cual difícilmente podrían encontrar ideas lascasistas quienes, como Concha (1969: 73), Davies (1979: 410) y Quint (1993: 169-172), han querido hallarlas en Ercilla. A pesar de su color lucaneo, la exaltación de los vencidos no debe explicarse en nuestros autores como una toma de partido en lo ideológico, sino como una consecuencia de la opción literaria por la cual se han inclinado, ya que la paridad de valor y de fuerzas entre bandos es propia del género épico (Davis, 2002: 132) desde sus modelos clásicos (Cristóbal, 1995: 76-77), a los que habría que añadir la tradición española de representación benévola del enemigo moro (Martínez, 2010: 175, n. 19). Por lo demás, la épica de Indias se ubica en la tradición celebrativa que venía leyendo la Eneida como panegírico desde Servio (v. Vilà, 2011: 151-152) y, ya con una clara simplificación de las ambigüedades que pudieran encontrarse en el texto latino, desde Petrarca y Boccaccio (v. Kallendorf, 1989 y Alves, 2001: 21-44). Bien notó Amor y Vázquez (1970: xxiv, xxxv-xxvi) que el enaltecimiento de los indios está subordinado en todo momento al de Cortés en el poema de Lasso, cuyo afán por defender los logros del conquistador de México de quienes pretendían restarles mérito lo lleva a incluir en la Mexicana de 1594 una "Apología en defensa del ingenio y fortaleza de los indios de la Nueva España” firmada por el licenciado Jerónimo Ramírez (Amor y Vázquez, 1970: 200-207).

${ }^{20} \mathrm{La}$ suficiencia del patrocinio humano como fuente de inspiración es un tópico panegírico, incorporado por primera vez a la épica latina por Lucano en su elogio de Nerón ("tu satis ad uires Romana in carmina dandas", 1.66), que se encuentra tanto en las invocaciones de Ercilla a Felipe II (Ar. 1.5; 16.2; 18.1-4; 23.87), dedicatario de su poema, como en la de Lasso a Hernán Cortés ( $C V$ 1.7-8), protagonista del suyo.

${ }^{21} \mathrm{No}$, hay, en efecto, una diferencia esencial entre metonimias tan manidas y reiteradas como la de Apolo por el sol ( $A r$. 2.48.5, 57.5; 7.40.6, etc.; $C V$ 3.39; 9.52.1-4; 10.57.1, etc.) y la de Marte por la guerra $(A r .1 .10 ; 2.73 ; 4.85 ; 5.32 ; 24.53$, etc.; $C V 1.1 .1,19.5,68.3 ; 2.11 .1,34.4$; 4.18.5, etc. ), o viejas personificaciones como la de la Fama (Ar. 4.80; 7.10; 16.1; 17.29; CV 7.41.7-8; 10.1.7), y pasajes como aquellos en los cuales las furias Tisífone y Alecto encarnan el fragor de la batalla en Lepanto ( $A r$. 24.53) y la discordia en Veracruz ( $C V$ 9.19), o aquel otro en que Marte y Belona representan el ardor guerrero de Hernán Cortés ( $C V$ 9.52.5-6).

${ }^{22}$ Mientras que Ercilla utiliza la aparición de Belona (17.38-60), como la de la Razón (18.29$65)$, para introducir en su poema digresiones acerca de la historia europea, al igual que hace con el mago Fitón (23.39-24), Lasso (9.42-45) se imagina a Neptuno y demás dioses del mar recogiendo los restos de las naves barrenadas por Cortés en un alambicado pasaje —inspirado quizás en el Carlo famoso de Luis Zapata (29.88.7-8) — que, si bien excede el sentido puramente metonímico que se da a Neptuno en la Araucana (15.57.6), es de todo punto marginal. 
Y la renuncia al aparato divino de la gentilidad no encuentra compensación en un sobrenatural cristiano reducido al mínimo y presentado en tono insistente como historia verdadera ${ }^{23}$. Desviarse de este camino — seguido, aun antes que por Ercilla, por Luis Zapata de Chaves en los pasajes de su Carlo famoso (Valencia, Juan Mey, 1566) en que relata, por primera vez en un poema épico, la conquista de México $^{24}$ - , apartarse, siquiera sea tentativamente, del realismo de la Araucana - entendido este no como estricta fidelidad a la historia, sino como reducción de la acción épica a un único plano, el terreno, que no excluye, por ficticias que sean, la tribulaciones ariostescas de hermosas indias enamoradas ${ }^{25}$ - , constituye toda una opción poética por la cual Gabriel Lobo, tras haber explorado en los dos últimos cantos de su Cortés valeroso las alternativas que enseguida analizaremos, se consideró obligado a dar explicaciones al lector ${ }^{26}$.

${ }^{23}$ La milagrosa participación del apóstol Santiago en la batalla de Cintla y la aparición de la Virgen a los indios durante el asedio de La Imperial son las únicas intervenciones celestes directas en, respectivamente, el Cortés valeroso (5.90-92; 6.1-14) y la Araucana (Ar. 9.13-17). Y es de notar que, aunque Lasso sigue con notable fidelidad a Gómara (cap. 20) en cuanto toca a Santiago, deja de lado la cautela del cronista ("creyeron que era el apóstol Santiago, patrón de España", Miralles Ostos, 1988: 34-35) para insistir en la verdad del caso (6.51-56) con énfasis que recuerda el empleado por Ercilla a propósito de la aparición mariana (Ar. 9.18-21). Acerca del posible modelo virgiliano (Aen. 8.520-536) del pasaje ercillesco, v. McManamon (1955: 162-163).

${ }^{24}$ Los pasajes dedicados al descubrimiento de América y a la conquista en tres de los cincuenta cantos del poema $(11.15-62,52 \mathrm{v}-55 \mathrm{r} ; 12.1-110,55 \mathrm{r}-60 \mathrm{v} ; 13.1-44,60 \mathrm{v}-63 \mathrm{r})$ fueron publicados separadamente por Medina (1916), a cuya selección añadió Reynolds y Toribio (1984) otras ciento una octavas en las que se narra lo sucedido desde la salida de Veracruz hasta la toma de México, acaecida el 13 de agosto de 1521 (14.38-129, 68v-73r), y la recompensa dada a Cortés por el emperador $(15.1-10,73 \mathrm{r}-73 \mathrm{v})$.

${ }^{25}$ Había insertado ya Zapata en su narración un episodio - basado quizás, como notó Medina (1916: 51, n. 12), en Gómara (cap. 16) - cuya naturaleza ariostesca fue reconocida por Amor y Vázquez (1958: 374-375) y por Chevalier (1966: 142); se trata de aquel en que Cortés se gana a los nativos de Cozumel librándolos de la opresión de dos monstruos, un águila y un tiburón ( $C F$ 12.29-67), y que parece haber sido imitado, al menos en parte, por Francisco de Terrazas (fr. 17, Castro Leal, 1941). Mas es a este a quien debemos, como ya advirtió Menéndez Pelayo (1911: 40-41) la introducción de los amores ercillescos entre indios en la épica de la conquista de México, aun cuando su episodio de Quétzal y Huítzel (fr. 4, Castro Leal, 1941) presente con respecto a la Araucana y la tradición ariostesca de la que esta bebe la particularidad de que es el varón el narrador.

${ }^{26}$ En esto se da una diferencia entre el Cortés valeroso y el Carlo famoso de Zapata, donde, de acuerdo con la convención estipulada en el aviso del impresor al lector, se marcan con asteriscos marginales como "ficciones" tanto los episodios ariostescos como las intervenciones sobrenaturales - ausentes estas, como ya se ha dicho, de los pasajes dedicados a la conquista de México, pero no de otros lugares de la obra-. 


\subsection{Un ensayo camoeniano}

La "variedad del onceno canto" a que se refiere Lasso en el prólogo consiste en la exaltación de Hernán Cortés mediante una fiesta sobrenatural que, por industria de Marte y Minerva, se le tributa al conquistador en Tlaxcala ${ }^{27}$. Se trata de una digresión compuesta por material heterogéneo, cosa que el propio autor reconoce en la última octava de un proemio que, a diferencia de lo que ocurre en los demás cantos — con la excepción del primero- no tiene contenido moral, según el modelo ariostesco seguido por Ercilla, sino metaliterario ( $C V$ 11.1$5)^{28}$. Mas, por la manera en que representa la retribución de los méritos del héroe sub specie fabulae, el entero canto recuerda mucho, como ya señalaron García Icazbalceta (1884: 415), Pierce (1961: 286) y Amor y Vázquez (1970: xxv), la isla de los amores en la cual, por iniciativa de Venus, festejan las ninfas marinas a Vasco de Gama y a sus hombres en los Lusíadas $(9.18-10.143)^{29}$. Es cierto que, como ha notado Pullés-Linares (2005: 66), se echa en falta en Lasso el gozoso erotismo de Camões — conjurado, eso sí, por una interpretación alegórica que hace pasar los favores de las ninfas por figura de los honores y la fama debidos a los portugueses en pago de sus proezas (Lus. 9.89) - . Permanecen, sin embargo, la descripción del locus amoenus en que tiene lugar el agasajo y la profecía ex eventu con la que este concluye, elementos que enmarcaban los amores de los portugueses con las ninfas en los Lusíadas $(9.54-63$; 10.6-143) у que en el Cortés valeroso $(11.23-37 ; 11.59-81)^{30}$ sirven respectivamente de pró-

${ }^{27}$ La palabra "fiesta" es utilizada en el texto repetidamente (11.16.6, 22.6; "festejado", 11.11.5).

${ }^{28}$ No deja de ser significativo que, a la hora de apartarse del paradigma ercillesco, Lasso (1.5) recurra precisamente a la metáfora del ramillete de flores, empleada repetidamente en la Araucana $(15.5,20.4)$ como tropo por la "variedad" poética que anhela el autor constreñido por las restricciones de la épica marcial.

${ }^{29}$ Poema publicado en 1572 (Lisboa, Antonio Gõçalves) al que Lasso, de no conocer el portugués, habría podido acceder a través de dos traducciones españolas impresas en 1580, la de Benito Caldera (Alcalá de Henares, Juan Gracián) y la de Luis Gómez de Tapia (Salamanca, Juan Perier); v. Peña (1994: 291).

${ }^{30} \mathrm{El}$ ámbito de la profecía es, no obstante, más restringido en Lasso que en Camões, ya que el español pone en boca de la ninfa Calianera noticias relativas a la descendencia de Cortés, mientras que el portugués había hecho que Tetis anticipara las futuras gestas de sus compatriotas en las Indias Orientales. La profecía del Cortés valeroso recuerda, pues, en esto los vaticinios dinásticos de Ariosto (OF 3.20-62; 41.64-67; 46.85-98) —a los cuales ha opuesto Everson (2001: 312) la amplitud patriótica del de los Lusíadas - y de Tasso (GL 17.89-94). No deja de ser significativo a este respecto que Lasso haya reescrito la lamentación de Anquises por la temprana muerte de Marcelo, sobrino de Augusto (Aen. 6.860-886) para referirse a la de doña Ana de Arellano, primera mujer de don Martín Cortés ( $C V$ 11.75-76), en un pasaje que no parece por lo demás ajeno al elogio que había hecho Ercilla de su propia esposa (Ar. 18.73), ni al lamento de Zapata por la muerte de la suya ( $C F$ 12.5-11). La referencia al propio poeta como futuro cantor de las glorias de su héroe ( $C V$ 11.79-80), ausente en Camões, tiene antecedentes en el África de Petrarca (2.441-454; 9.216-268) y en la Cristíada de Marco Girolamo de Vida (6.880-897). 
logo y epílogo a la espectacular reversión de las metamorfosis de Ovidio (11.4648) que, de acuerdo con el programa adelantado por Júpiter (11.18) constituye el número central de la función ${ }^{31}$. Se diría, pues, que, aun conservando hasta cierto punto las estructura del pasaje, así como el sentido alegórico encomiástico que a este le había asignado Camões, nuestro autor ha sustituido el lujuriante jardín del amor de color romacesco ${ }^{32}$ por un vistoso espectáculo escénicomusical $^{33}$ que evoca el aparato de las fiestas de corte ${ }^{34}$. Pero la deuda del penúltimo canto del Cortés valeroso con los Lusíadas no se ciñe a los dos cantos finales de la epopeya portuguesa. En el canto 11 Gabriel Lobo ha imitado no sólo un episodio concreto del poema de Camões, sino también la motivación mitológica de los acontecimientos humanos que sobrevuela en todo momento el relato del lusitano. Marte y Minerva se presentan ante Júpiter para interceder por un heroico mortal (11.6-19) ${ }^{35}$, y al hacerlo se ajustan a un esquema narrativo que es el habitual para desencadenar los acontecimientos en la épica desde Homero $^{36}$. Y este antiguo esquema se respeta igualmente cuando, aceptada la

${ }^{31}$ Las ninfas Dafne (11.46.5-8), Clicie (11.47.1-2), Cíane (11.47.3-4) y Aretusa (11.48.), así como la humana Mirra (11.47.5-4), dejan de ser, respectivamente, laurel, girasol, fuentes y árbol de mirra para recuperar su anterior figura (cf. Met. 1.452-567; 4.206-270; 5.409-437, 571-641; 10.298-502). Bien ha señalado Marrero-Fente (2015: 283-284; 2017: 211) los paralelismos que en el texto de Lasso remiten al de Ovidio, como son el recordatorio de que "ningún dios puede / deshacer... lo que otro ha hecho" (11.18.1-2, Met. 3.336-337), la enumeración de las divinidades menores (12.19, Met. 1.191-192), y la referencia a la Vía Láctea (12.20.3, Met. 1.168-171).

${ }^{32}$ A la deuda de la paradisíaca isla camoeniana con el jardín de Alcina ( $O F$ 6.20 y sigs.), y aun con el de Logistila ( $O F 10.58$ y sigs.), relativizada quizás en exceso por Bowra (1945: 127128), habría que sumar la que la efusión sexual colectiva pueda tener con el episodio de los argonautas y las isleñas de Lemnos en las Argonáuticas de Valerio Flaco (2.341 y sigs.), señalada por Post (1958: 7); "segundos argonautas" llama el narrador a los portugueses en el momento en que desembarcan en la isla de Venus (Lus. 9.64.2).

${ }^{33}$ El elemento musical, ya presente en Camões (9.64.5-8), es amplificado por Lasso mediante la introducción de un catálogo de músicos míticos (11.43-45) que responde en su especie a los precedentes de árboles (29-33), jardines (34-35) y pintores (37), todos ellos tomados, como ha señalado Pullés-Linares (2005: 65) de Ravisius Textor (Wolffhart, 1581: cols. 854-860, 140-142, 145-146, 931-936) — aun cuando no deba excluirse en el de árboles la dependencia directa de Ovidio (Met. 10.88-107) propuesta por Marrero-Fente (2015: 286-287 y 2017: 215) -.

${ }^{34}$ Fue esta una sustitución acorde, quizás, con los tiempos; piénsese que en la edición censurada de los Lusíadas conocida como "edição dos Piscos" (Lisboa, Manoel de Lyra, 1584), publicada el mismo año en que está fechada la aprobación del Cortés valeroso, fueron suprimidas las estrofas que describían con más lujo de detalles los amores de los portugueses con las ninfas $(9.71-73,78,83)$.

${ }^{35} \mathrm{El}$ hecho de que sean precisamente los dioses de la prudencia y de la guerra quienes interceden por Hernán Cortés hacen de este una especie de "encarnación de la sabiduría, el valor y el arte bélico" (Amor y Vázquez, 1970: XXV). Marte y Minerva se presentan, sin embargo en el texto más como personajes divinos con plena capacidad de actuación que como personificaciones de la guerra, o de las armas y las letras — posibilidad esta última comprometida por el carácter más guerrero que letrado que otorga Gabriel Lobo (CV 11.13-4-8) a su Minerva_; v. Marrero-Fente (2017: 209).

${ }^{36} \mathrm{La}$ intercesión de una diosa ante Júpiter en favor de un humano se remonta a la de Tetis en favor de Aquiles (Il. 1.495-516) y a la de Atena - la Minerva de los romanos - en favor de 
súplica, envía Júpiter a Mercurio a la tierra con el encargo de que disponga lo necesario para la celebración del festejo en homenaje a Hernán Cortés. No diversos eran los procedimientos de la epopeya histórica "à la manière de Virgile" (Puibusque, 1843: 280) propuesta por Camões, con la cual parece coquetear Lasso cuando atribuye a la intervención del mensajero divino el acuerdo de paz entre españoles y tlaxcaltecas $(11.21)^{37}$ :

Júpiter a Argifonte al punto envía y despacha veloz del alto cielo, el cual de Tlaxcallán tomó la vía, rompiendo el aire con sonoro vuelo; inspira a la ofendida compañía que habitaba el remoto y fértil suelo: mitigan su rigor los tlaxcallanos, y efetúan la paz con los cristianos.

El modelo de nuestro autor es aquí el célebre pasaje de la Eneida en el que Júpiter, atendiendo inmediatamente los ruegos de Venus en favor de Eneas, envía a Mercurio a Cartago a fin de que los habitantes de esta ciudad reciban con benevolencia a los náufragos troyanos (1.297-304); el mismo que había empleado Camões para propiciar mediante una injerencia divina semejante la admisión de los portugueses en Melinde (Lus. 2.56-58). ${ }^{38}$ La diferencia estriba

Odiseo (Od. 1.44-62), aunque, naturalmente, el modelo principal de Lasso es la de Venus en favor de Eneas (Aen. 1.223-296), que antes lo había sido de Camões (Lus. 2.33-55). Especialmente notable es el eco de Virgilio ("oscula libavit natae, dehinc talia fatur", Aen. 1.256), así como la mediación de Camões ("na face a beija", 2.42.6), en la descripción que hace Lasso de las muestras de afecto dadas por Júpiter a Minerva ("le responde besándola en la frente, / diciendo", 11.14.2-3). La fiesta en honor de Cortés toma, pues, como modelo el episodio camoeniano de la isla de los amores, pero lo motiva de modo similar a como el portugués — que había hecho depender el desencadenamiento de dicho episodio no de la súplica de una diosa a Júpiter, sino de un amable encargo de Venus a Cupido (Lus. 9.37-42) - había motivado, a la manera de Virgilio, la acción principal de la epopeya.

${ }^{37}$ El Argifonte (11.21.1) es Mercurio "el matador de Argos" (lat. Argiphontes) y no el propio monstruo Argos, como parecen haber entendido Pullés-Linares (2005: 312 n. 42) y Marrero-Fente (2015: 284 y 2017: 212); e igualmente a Mercurio, y no a "Ligeo, rey de Acarnania" (PullésLinares, 2015: 313 n. 45) hay que referir "Lygio" (11.22.5), puesto que el epíteto Lygius, que debe de ser corrupción de Polygius (Пoגúrıos, Paus. 2.31.10) —traducido por Natale Conti (1568: 339r) en la explicatio nominum de sus Mythologiae como "multam habens terram"-, se aplica a este dios en los diccionarios de Calepino y de Stephanus.

38 Reelaborado por Virgilio a partir de Homero (Il. 24.331y sigs.; Od. 1.81y sigs.; 5.28y sigs.), el descenso del mensajero divino a la tierra dio lugar a un tópico de cuya recurrencia en la épica se sirvió Greene (1963) para estudiar la tradición del género. Por cuanto atañe al texto de la Eneida seguido por Lasso, se diría que no es ajena al "mitigan su rigor los tlaxcallanos" (11.21.7) la versión que del "ponuntque ferocia Poeni / corda" (Aen. 1.302-303) había dado Hernández de Velasco ("ablandan su rigor los africanos"; 1555: 4v). 
en que, en el Cortés valeroso (10.91-96), las paces han sido hechas por medios enteramente naturales ya antes del descenso de Mercurio. Así, Gabriel Lobo ofrece dos versiones alternativas de un hito de la conquista de México como fueron los acuerdos de amistad entre españoles y tlaxcaltecas. La primera versión se limita a narrar el acontecimiento en el plano terreno, siguiendo el relato de Gómara (cap. 53, Miralles Ostos, 1988: 82-85) acerca de la llegada al campamento español del capitán tlaxcalteca Xicoténcatl en son de paz ${ }^{39}$, mientras que la segunda proporciona al devenir humano un correlato en el plano celeste, estableciendo entre las acciones de arriba y las de abajo una relación de causa a efecto. La primera sigue el patrón lucaneo de la Araucana, observado por Lasso en los diez primeros cantos de su epopeya, mientras que la segunda acaricia, por primera vez en la obra, la posibilidad de contar lo mismo a la manera de Virgilio, como, a pesar de lo histórico y de lo reciente de los acaecimientos narrados, había hecho Camões en los Lusíadas. El problema es que entre la opción de Ercilla y la de Camões existe, como ya apuntó Figueiredo (1953: 381), una desigualdad radical, de la cual Lasso se muestra consciente. Abandonado el aspecto venéreo ${ }^{40}$, el jardín de las delicias, que, desde la estancia de Eneas en Cartago, representaba la alternativa romancesca a la gloria guerrera

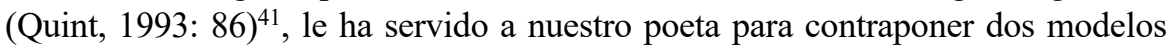
de causalidad narrativa, el humano y el sobrehumano, que difícilmente pueden combinarse. En consecuencia, la motivación divina de la acción épica al modo virgiliano-camoeniano en el canto 11 del Cortés valeroso es apenas un ensayo, un desvío pasajero presentado desde el prólogo como una concesión al otium frente al negotium constituido por el deber de celebrar la conquista de México procurando "excusar todas poesías, pues la mezcla de ellas suele causar menos opinión y autoridad a la historia", según la advertencia hecha al autor por don Martín Cortés, hijo del conquistador, en carta fechada en Madrid a 13 de julio

39 Al igual que en Gómara, Xicoténcatl se presenta de improviso en el campamento español con la oferta de paz, y su llegada (11.91-92) se inserta entre la intervención de Cortés para aplacar los rumores de algunos sediciosos (11.76.5-11.90) y las capitulaciones (11.93-94), inmediatamente seguidas por la recepción de los forasteros en Tlaxcala (11.95-96).

${ }^{40}$ A pesar de que, como sugirió Amor y Vázquez (1970: xxv), la referencia de la crónica de Gómara a las mujeres tlaxcaltecas entregadas a los españoles (cap. 54, Miralles Ostos, 1988: 84) podría haber dado pie a la introducción del erotismo, si Lasso hubiera querido imitar a Camões más de cerca.

${ }^{41}$ La vinculación entre la isla camoeniana y el Cartago virgiliano fue notada ya por Faria y Sousa (1639: IV, col. 23A-B). Alves (2001: 590-599) ha mostrado que muchas de las críticas que este pasaje le granjeó a Camões se debieron precisamente a que, en lugar de hacer del lugar de delicias y del amor carnal por su dueña una alegoría del vicio superado por el héroe - como, siguiendo las interpretaciones panegírico-morales de la Eneida, había hecho Ariosto con el jardín de Alcina ( $O F \quad 6.20$ y sigs.) — , prefirió hacer del paraje vicioso una alegoría de los premios merecidos por la virtud heroica. 
de 1582 y reproducida entre los preliminares de la obra (Pullés Linares, 2005: $122)^{42}$. Esto no quiere decir, sin embargo, que Gabriel Lobo, una vez concluido el canto 11, que es no sólo un ejemplo de "partición" (11.1.2) y de "variación" (11.2.1) con respecto al resto del poema, sino también un erudito juego con la tradición de la épica de componente mitológico a la manera de Virgilio y de Camões - cacería $^{43}$, tormenta ${ }^{44}$ y musas $^{45}$ incluidas - regrese sin más a la senda de Ercilla y de Lucano.

\subsection{El viraje tassesco}

Finalizado el excurso constituido por el canto 11, se prosigue en el 12 el relato del avance de Hernán Cortés desde la matanza de Cholula hasta la prisión de Moctezuma. Al igual que había hecho en los cantos 1-10, Gabriel Lobo

${ }^{42}$ El empleo de palabras y expresiones pertenecientes al campo semántico del ocio hace coincidir el reposo del lector - invitado en el prólogo a "recrear el ánimo cansado de tantas veras y verdades" con las fícciones de los cantos 11 y 12 (Pullés-Linares, 2005: 132) - con el del héroe - agasajado con una fiesta calificada de "holgura" por Júpiter (11.18.7) poco antes de enviar a Mecurio a disponer el prado "para que Cortés mejor se solazase" (11.22.4) —; y a ambos subyace el desahogo creativo del propio autor, que hasta el canto 10 ha observado rigurosamente las prescripciones de su mecenas. Acerca de la relación de Lasso con los Cortés, v. Franco Carcedo (1994: 11-12, 15), Weiner (2005: 93-120) y Martínez (2010: 176).

${ }^{43}$ La montería organizada por los tlaxcaltecas en honor de Cortés - que carece de sustento histórico en López de Gómara, aunque pueda deber algo al capítulo dedicado por el cronista a las fastuosas cacerías de Moctezuma (84, Miralles Ostos, 1988: 122-123) - está modelada en su comienzo (10.97-100) sobre la organizada por Dido en honor de Eneas (Aen. 1.129-132), y la persecución del "cerdoso animal" que lleva a Cortés al lugar designado para la fiesta (10.101-105, 11.23), aunque tiene un modelo cercano en el pasaje de la Araucana (23.27-30) en que una corza lleva a Ercilla hasta la cabaña de Guaticolo, presenta concomitancias con la caza de Ascanio (Aen. 7.475-499).

${ }^{44}$ Entre la descripción del locus amoenus donde se ha de celebrar la fiesta y el catálogo de los músicos míticos inserta Lasso la descripción de una inesperada tormenta (11.38-41) que podría estar inspirada en la que interrumpe la cacería de Dido y Eneas (Aen. 4.160-164), pero que carece aquí de función alguna, como no sea la de evocar, con la descripción del combate entre los vientos, el célebre pasaje virgiliano (Aen. 1.81-91) que ha servido de modelo a una larga sucesión de tempestades épicas, acerca de las cuales v. Cristóbal (1988).

${ }^{45}$ La referencia a las musas que hace Calianera al profetizar que Lobo cantará la gesta de Cortés "de las nueve alentado del Parnasso" podría pasar por tópica, pero no deja de llamar la atención que se inserte precisamente en el canto 11 (79.4), después de que, en los diez cantos ercillescos, el poeta haya rechazado expresamente la inspiración de estos seres míticos para buscarla ya en Cortés (1.7-8), ya en Jesús (6.51-52), despreciando el poder de la fuente Hipocrene ("la Caballina" 1.7.3; "el Cabalino don", 6.51.4 ) en términos que evocan la invectiva contra la poesía mitológica contenida en el prólogo de las Sátiras de Persio ("nec fonte labra prolui caballino / nec in bicipiti somniasse Parnaso / memini", 1-3). Lasso volverá a hacer alusión a Apolo, al Parnaso y a las Musas — que nunca invoca directamente - cuando se disponga a relatar la prisión de Moctezuma (12.62). 
da a estos acontecimientos un enfoque terreno a la manera de Ercilla, a quien debe además en parte los amores de Gualca y Alvarado (12.16-28), que le permiten ofrecer una versión del descubrimiento de la traición de los cholultecas diversa de la de Gómara en el único pasaje en que se aparta del cronista ${ }^{46}$. Pero el derribo de los dioses del templo mayor inquieta a Lucifer, quien envía al ídolo mexicano Tezcatlipuca a la casa de la Envidia (12.91.4-105) para que esta vaya a Cuba a incitar a Diego Velázquez contra Hernán Cortés. La idea parece haberla tomado Lasso de Luis Zapata, en cuyo Carlo famoso (20.103 y sigs., f. 108r y sigs.) Satanás visita por sí mismo la casa de la Envidia para que esta vaya a París a incitar a Francisco I contra Carlos $V^{47}$. Hace, sin embargo, nuestro poeta que el recurso a la Envidia se decida en una asamblea de demonios que es la primera que se encuentra en una epopeya de Indias escrita en lengua romance (12.86-92); y el modelo de esta debió de ser concilio infernal descrito por Tasso en su Jerusalén liberada (4.1-19), aun cuando los paralelismos formales entre ambos pasajes sean menos reseñables que su equivalencia funcional ${ }^{48}$. Faltan en el Cortés valeroso los montruos míticos que pueblan el inframundo virgiliano ${ }^{49}$ y el indignado discurso de un demonio identificado explícitamente con el dios

${ }^{46}$ A pesar de que Lasso resume a Gómara, suprimiendo numerosos pasajes descriptivos, es posible reconocer a primera vista la deuda que tiene su relato con el del cronista en cuanto respecta al paso por Cholula (caps. 59-60, Miralles Ostos, 1988: 90-92; CV 12.1-15, 29-41), la 1legada a México (cap. 65, Miralles Ostos, 1988: 98-99; $C V$ 12.47-55), la prisión de Moctezuma (cap. 83, Miralles Ostos, 1988: 120-122; CV 12.56-80) y el derrocamiento de los ídolos del templo mayor (caps. 85-86, Miralles Ostos, 1988: 123-126; CV 12.81-85). Acerca de Gualca y Alvarado, v. s. nn. 15 y 16.

${ }^{47}$ Blanco (2013: 21) remite el pasaje de Zapata a los Cinque canti de Ariosto, obra en la que el hada Alcina le hace una visita a la Envidia para empujarla a mover al traidor Ganalón (1.38-56).

${ }^{48}$ En De gestis Mendi de Saa (Coímbra, 1563), epopeya acerca de las hazañas del tercer gobernador del Brasil compuesta en hexámetros latinos por el P. José de Anchieta, en la que Cañizares-Esguerra (2008: 65) ubica el comienzo de la que él denomina "épica satánica de origen ibérico", se representa el rabioso clamor del infierno ante los avances del cristianismo en las tierras conquistadas por los portugueses (vv. 1160-1182 de la ed. de Fornell Lombardo, 1992: 144 147), pero no un concilio infernal propiamente dicho. El que se encuentra en la Columbeida latina de Julio César Stella (2.405-470) — cuya edición romana definitiva (y presentada como primera) data de 1589 , aunque fue precedida por una londinense fechada en 1585 y reimpresa en Lyon ese mismo año (Sánchez Quirós, 2010: xcvii-ciii) — es ya deudor del de la Jerusalén liberada de Tasso (4.1-19) — de la cual toma Stella en otro lugar (1.94-98) la comparación del aliento del diablo con los vapores emitidos por el volcán Etna (GL 8.1-4) —. Fuera del ámbito de la épica indiana, son ya tassescos los monólogos diabólicos de la Austríada de Juan Rufo (20.57-63; 21.6-13; 1584: 354r-355r, 365v-366v), aprobada en 1582 e impresa por Alonso Gómez en Madrid en 1584, y el concilio infernal del Monserrate de Cristóbal de Virués (1.8-19; 1587: 2r-4r); esta última obra fue impresa en Madrid por Querino Gerardo en 1587, un año antes que la de Gabriel Lobo, pero la cronología relativa se invierte si atendemos a las fechas de las aprobaciones, ya que la del Monserrate data de 1586 y la del Cortés valeroso de 1584.

${ }^{49}$ Homenaje a la Eneida (6.285-289) presente en Tasso (GL 4.5), y antes en la Cristíada de Vida, publicada en 1535 (1.143-145). 
pagano Plutón, pero el objeto de la deliberación es, como lo era en la Liberada, impedir el feliz desarrollo de la acción épica - mientras que en el Carlo famoso el objeto de la intervención diabólica era mover los acontecimientos que habrían de llevar a la batalla de Pavía- Si la reducción a un solo diablo de la tumultuosa legión infernal despachada a la tierra en la Liberada (4.18) $-\mathrm{y}$ antes en la Cristíada (1.224-235) de Marco Girolamo Vida - puede achacarse a la influencia de Zapata, la identificación de dicho diablo con el el ídolo mexicano Tezcatlipuca es ciertamente original ${ }^{50}$. Al hacer que este sea despachado a la casa de la Envidia, Gabriel Lobo traslada nuevamente al lector desde el contexto mexicano — reforzado por la celebración del estruendoso consejo en el volcán Popocatépetl (12.88-90) $)^{51}$ — al ámbito clásico, y en concreto al pasaje de las Metamorfosis de Ovidio (2.760-805) en el que Minerva visita la casa de la Envidia para encargarle a esta que ejerza su influencia sobre la joven Aglauro ${ }^{52}$. Tanto en la Liberada como en las Metamorfosis se nos presenta un poder sobrehumano que influye en los asuntos terrenos excitando un afecto en los personajes humanos, pero la mediación de Zapata, que había utilizado a su vez el pasaje ovidiano, ha hecho que, a la hora de elegir el afecto en cuestión, Lobo Lasso haya preferido la Envidia del poema latino a los amores del poema italiano ${ }^{53}$.

50 Aun cuando la identificación de los dioses de los indios con los demonios era - huelga decirlo - habitual desde el punto de vista español. Ha sido planteada por Lasso desde la descripción etnográfica con que abre su relato (1.15-16), y se enfatiza en el caso de Tezcatlipuca, llamado reiteradamente "ídolo" $(12.106 .1,108.1)$, mediante la mención de la rica vestidura "que en México tenía” (12.91.7-9; cf. 12.102.7-8); v. i. n. 52.

${ }^{51}$ A la descripción del volcán, deudora de Gómara (cap. 62, Miralles Ostos, 1988: 93-94), como bien ha notado Amor y Vázquez (1970: 162 n. 7) a propósito del pasaje correspondiente de la Mexicana (21.38-42), le añade cierto color virgiliano (Aen. 8.416-425) la comparación del Popocatépetl con la fragua de Vulcano ( $C V$ 12.90.4-6), que los antiguos ubicaban bajo el Etna - mencionado con el nombre italiano de Mongibello en el concilio infernal tassesco (GL 4.8.1-2) -

52 A pesar de lo numeroso de los lugares paralelos (12.94.2, Met. 2.762; 12.94.7-8, Met. 2.760; 12.101.5-7; Met. 2.768-9; 12.102.1, Met. 2.770; 12.103.2, Met. 2.774; 12.104.1, Met. 2.775; 12.104.3, Met. 2.775; 12.104.6, Met. 2.776; 12.105.1, Met. 2.779; 12.105.6-7, Met. 2.778; 12.106.8, Met. 2.784; 12.108.4-5, Met. 2.793-794; 12.111.4-8, Met. 2.798-799; 12.112.1, Met. 2.803-804), Lobo se permite contradecir a su modelo ("non ulli pervia vento", Met. 2.762) en un caso ("el Aquilón furioso combatía" 12.94.6) en el que ya lo había contradecido Zapata ("donde jamás entró en ningún momento, / si no es el Regañón, nunca otro viento”, CF 21.5.7-8, 108v), y en otro muy notable reescribe la aflicción de la Envidia ovidiana ante la belleza de Minerva ("utque deam vidit formaque armisque decoram", Met. 2.773) atribuyéndola a la riqueza del atavío de Tezcatlipuca ("ella se aflige con riqueza tanta / y se entristece en verle cobijado / todo con planchas de oro reluciente / y ocho esmeraldas gruesas en la frente", 12.102.5-8), para cuya descripción toma de Gómara (cap. 81, Miralles Ostos, 1988: 119), con leves modificaciones, los detalles relativos al oro y a las esmeraldas. Ha incluido, además, en su casa de la Envidia un catálogo de célebres envidiosos antiguos que, como ha notado Pullés Linares (2005: 343 nn. 216-218, 344 nn. 222-224, 227-228, 230232, 345 n. 237), procede de Ravisius Textor (Wolffhart, 1581: cols. 1170-1173).

${ }^{53}$ El demonio de Tasso es en principio poco explícito acerca de los medios a utilizar para lograr su propósito, pero pronto se hace patente que el primero de ellos consistirá en excitar en 
Mas, si el afecto personificado es ovidiano, la finalidad de su intervención es, como la del concilio infernal que la precede, tassesca. Movida por el diablo cristiano, y no por una diosa pagana como Minerva, la Envidia no entra en la acción narrativa para encaminarla hacia su conclusión, como un eslabón más de la cadena causal que lleva a la metamorfosis de Aglauro en piedra, sino para intentar impedir que el desenlace previsto, que es en Lasso la conquista de México como en Tasso lo era la de Jerusalén, sea alcanzado ${ }^{54}$.

Hay que tener en cuenta que, si este pasaje entero, y no sólo la descripción de la casa de la Envidia, constituye - como nos parece - la segunda de las excepciones a la regla de la fidelidad a la historia mencionadas en el prólogo, no nos encontramos ahora frente a una mera digresión como la del canto 11. El viaje de Tezcatlipuca a la casa de la Envidia sirve para procurar una motivación sobrenatural a un hecho tan relevante como el desembarco de Pánfilo de Narváez en México, que obliga a Cortés a dejar la ciudad de Moctezumadonde, bajo su lugarteniente Pedro de Alvarado, se producirá la matanza del templo mayor - para dirigirse precipitadamente a Veracruz — donde rendirá al enviado de Velázquez, cuyas tropas incorporará a las suyas-. Y, a diferencia de lo que ocurría en el canto 11 con la paz entre españoles y tlaxcaltecas, esta motivación ultraterrena no se superpone a una versión realista del mismo acontecimiento, contada previamente a la manera de Ercilla de acuerdo con los datos proporcionados por Gómara. Con la irrupción de la figura de Lucifer, el concilio infernal, el envío de Tezcatlipuca a la casa de la Envidia y la acción de esta sobre Velázquez y sus partidarios, Gabriel Lobo abandona el patrón ercillesco para incorporar a su narración un plano sobrenatural cuyos habitantes no son ya los dioses de Virgilio y de Camões, con los cuales se ha limitado a ensayar fugazmente en el canto 11, sino los demonios de Tasso.

En cuanto Pánfilo de Narváez parte de Cuba, Lasso regresa a México para narrar el ajusticiamiento de Qualpopoca, la prisión de Cacama y la obediencia de Moctezuma a Carlos V en tres octavas y media (12.115-118.1-4) que resumen considerablemente, pero no alteran, el relato que de estos sucesos se encuentra en López de Gómara (caps. 87-89, 91, 92, Miralles Ostos, 1988: 126-

\footnotetext{
los caballeros cruzados el amor por la maga Armida ( $G L 4.23$ y sigs.). Una función idéntica desempeña la pasión amorosa - el mismo afecto que quiso utilizar Juno para evitar que Eneas cumpliera su misión (Aen. 4.90 y sigs.) - en la notablemente tassesca Columbeida de Julio César Stella (2.434 y sigs.).

${ }^{54}$ En Claudiano, que traslada al infierno el tópico épico del concilio de los dioses, la asamblea sirve para poner en marcha la acción narrativa, esté esta constituida por el rapto de Prosérpina (Rapt. 1.38 y sigs.) o por los males provocados a la humanidad por Rufino (In Ruf. 1.25 y sigs.), no para obstaculizarla. Entre los concilios infernales estudiados por Moore (1918), el del Filocolo de Boccaccio (1.9) es el primero en el que los demonios deciden estimular en un mortal - Lelio - un afecto - el miedo - para intentar impedir que se lleve a cabo una acción prevista — la peregrinación a Santiago-.
} 
127, 129-132). Mas enseguida la que Gómara llamó "vuelta de Moctezuma" (cap. 94, Miralles Ostos, 1988: 134) le ofrece la oportunidad de poner otra vez en juego al infierno en un pasaje cuya introducción no disculpa en el prólogo, seguramente porque ya el cronista había achacado al demonio el cambio de opinión que había llevado al señor de México a pedirle a Cortés que se marchase. De las tres razones aducidas por Gómara para explicar la mutación en la actitud de Moctezuma hacia los españoles, nuestro autor obvia las dos puramente humanas - la presión ejercida por los notables sobre el rey y la pesadumbre de este por el encarcelamiento de su sobrino Cacama- y se basa en la tercera para insertar en su relato una nueva intervención diabólica. El demonio se le aparece a Moctezuma bajo el aspecto de Acamapich, lejano predecesor suyo, y lo incita a matar o a expulsar de sus dominios al capitán español (12.118.5-125.2). Aunque la conversación de Moctezuma con el diablo, al igual que el nombre y la historia de Acamapich, está tomada de Gómara ${ }^{55}$, el modo en que Lasso la recrea, otorgándole la palabra a un ser procedente del inframundo que se presenta bajo la figura de alguien conectado de alguna manera con el personaje a quien pretende persuadir, se remonta en última instancia a la visita que, bajo la apariencia de la sacerdotisa Cálibe, había hecho la furia Alecto a Turno para exhortarlo a romper hostilidades con Eneas (Aen. 7.406-434) ${ }^{56}$. El que la res-

${ }^{55}$ Lasso ha concentrado en un único y perentorio mandato ("que a esta gente brava, cauta, odiosa, / mates o envíes luego de tu estado", 12.124.5-6) los reiterados coloquios con el diablo a que se refería Gómara ("otra [razón] fue que el diablo, como se le aparescía, puso muchas veces en el corazón a Moteczuma que matase los españoles o los echase de allí”; cap. 94, Miralles Ostos, 1988: 134). El mérito en el engrandecimiento del "imperio y nombre mexicano" atribuido a Acamapich por el cronista (cap. 211, Miralles Ostos, 1988: 292) es evocado por el épico cuando le hace decir, refiriéndose al estado de Moctezuma, "este reedificó mi real persona / para que tú, imprudente, acobardado, / vinieses a perder con flaca mano, / y su temido nombre mexicano" (12.122.5).

${ }^{56}$ Aun cuando no haya claros ecos textuales - con la excepción de la "llama viva y pura" que a Acamapich "por los ojos le salía" (12.120.6-7), que podría remontarse al flammea torquens lumina virgiliano (Aen. 7.448-449) - , no deja de llamar la atención que el diablo de Lasso haya sustitudo los agravios propios de que se quejaba el de Gómara ("le atormentaban y daban enojo las misas, el evangelio, la cruz y el bautismo", cap. 94, Miralles Ostos, 1988: 134) por una relación de las ofensas infligidas por Cortés a Moctezuma (12.123), deudora seguramente del recordatorio que de los ultrajes inferidos por Eneas a Turno hacía a este la Alecto de Virgilio (Aen. 7.421-424). Podría, quizás, hallarse otro antecedente clásico en la aparición de la sombra del difunto Layo bajo el aspecto de Tiresias a Etéocles en la Tebaida de Estacio (2.89-129), que comparte con nuestro caso el detalle de que el aparecido ha precedido en el trono a aquel a quien se aparece, así como un eco de Camões (Lus. 8.51.7) en el hecho de que la aparición provoque la inmediata convocatoria de un consejo de notables ( $C V$ 12.125-3). La aparición de Eponamón a los araucanos durante el asedio de La Imperial (Ar. 9.10-11) — que, como ha hecho notar Nicolopulos (2000: 14 n. 10), evita hacer exhibición de imitación - no es comparable a la que nos ocupa ni por la forma - el demonio se presenta bajo el aspecto de un dragón- ni por la función ya que los ánimos que da a sus adoradores son dejados enseguida sin efecto por la aparición de la Virgen-. Fray Andrés de Olmos proporciona en un texto náhuatl (Baudot, 1972: 354 y 1979: 89-90) una curiosa noticia acerca de una aparición del diablo engalanado como un rey prehispánico, pero nada permite asegurar que Lasso haya tenido acceso a una información análoga. 
ponsabilidad última de esta acción corresponda a un infierno enfrentado por su cuenta al cielo, y a no a una diosa celeste que utiliza a una criatura infernal para oponerse al designio de otros dioses celestes, como hace Juno con Alecto en la Eneida, nos ubica, sin embargo, en un universo poético que tiene ya más que ver con el de Tasso que con el de Virgilio $^{57}$.

En su estudio acerca de la adaptación de la maquinaria divina de la epopeya antigua al monoteísmo cristiano, Tobias Gregory (2006: 12-14) emplea el concepto de "mosaic distinction", tomado de Jan Assmann (1997: 1), para referirse a la que es en su opinión la diferencia más importante entre la épica clásica y la épica renacentista: la distinción entre verdadera y falsa religión, que deja atrás las parcialidades caprichosas y negociables de los dioses olímpicos para sustituirlas por el enfrentamiento universal entre Dios y el diablo, cuyo respectivo favor divide entre bendecidos y réprobos los personajes y los bandos. Se trata de un dualismo enconado, sí, pero no maniqueo - ya que la libertad de actuación del diablo está limitada por la omnipotencia de Dios, cuya victoria en la cruz prefigura un triunfo final que se da por seguro- que es connatural a la religión cristiana, y que para los épicos del siglo XVI resultó, por tanto, inevitable, pero también productivo. Ya antes de que Tasso diera a la luz, con su Jerusalén liberada (1581), el más acabado ejemplo de epopeya de cruzada, el descubrimiento y conquista de las Indias había inspirado poemas que, en mayor o menor medida, proponían el conflicto entre fieles e infieles como legitimación última de las gestas que celebraban. Tal es el caso de las partes primera y segunda de la Araucana $(1569,1578)^{58}$ y el de los Lusíadas $(1572)^{59}$, y, en, el ámbito de la épica cortesiana, el del Carlo famoso de Luis Zapata (1566) y el del Nuevo Mundo y Conquista de Francisco de Terrazas (ca.

${ }^{57}$ Entre las intervenciones diabólicas que, por propia iniciativa de las potencias infernales, se producen en la Liberada, es la de de Alecto a Solimán bajo el aspecto de Araspes (9.8-11) la que más claramente está modelada sobre el patrón virgiliano. En la de Belcebú a Oradín bajo el aspecto de Clorinda (7.99-101) la influencia de Virgilio se ve sobrepujada por la de Homero (Il. 4.85-126).

${ }^{58}$ Reiteradamente pone Ercilla a los españoles, que presentan a los indios la expedición punitiva como misión evangelizadora (Ar. 16.29-30), bajo la protección de un Dios que está claramente de su parte (Ar. 8.67.5-8; 9.5-6; 15.74.1; 16.13.5-8), aun cuando a veces los castigue por sus pecados permitiendo que sus enemigos, adoradores del demonio (Ar. 1.40-41; 9.10-11; 8.39, 43, 63), los opriman (Ar. 1.69). Este partidismo religioso de la Araucana, menospreciado por Royer (1879: 206) y por Chevalier (1966: 145), ha sido puesto de manifiesto por Nicolas (1869: clxxiilxxvi, cclxv-cclxvii), McManamon (1955: 159-160, 173), Lagos (1981:163-164) y CañizaresEsguerra (2008: 72-74).

${ }^{59}$ La dimensión apostólica de la expedición de los portugueses a la India se expresa mediante la identificación de los ídolos con los demonios (Lus. 7.47), que alcanza su mayor grado de complejidad en la aparición de Baco bajo el aspecto de Mahoma (Lus. 8.46-50), así como a través del relato de la predicación y el martirio de Santo Tomás (Lus. 10.108-119). Han percibido bien la presencia de este dualismo en Camões Gregory (2006:14) y Cañizares-Esguerra (2008: 76-77). 
1570-1580 ${ }^{60}$. Si Zapata, tras relatar el prodigio, tomado de Gómara (cap. 145, Miralles Ostos, 1988: 207-208), del ángel que desciende a consolar a un cautivo que está a punto de ser sacrificado por los mexicanos (14.125.3-126), apostilla que el "perdimiento" de estos se debió a "la voluntad de Dios" (14.127.1$2,72 \mathrm{v})$, Terrazas, que ya en el que debió de ser proemio de su epopeya menciona los "dioses postrados falsos del profundo" (1.13), afirma reiteradamente el patrocinio de Dios sobre los españoles ${ }^{61}$, y presenta el encuentro de estos con su compatriota Jerónimo de Aguilar como prueba de la misión divina de Cortés ${ }^{62}$. Pero una cosa es postular que la conquista de México se ha llevado a cabo bajo la guía del cielo - como hace el propio Cortés en las Cartas de relación ${ }^{63} \mathrm{y}$, con énfasis considerablemente mayor y demostraciones portentosas, López de Gómara en su crónica ${ }^{64}$ _, en la idea de que, como afirma Lasso

${ }^{60}$ De este poema, que nunca llegó a imprimirse, poseemos tan sólo los pasajes citados — sin que de todos resulte clara la atribución, por Baltasar Dorantes de Carranza en su Sumaria relación de las cosas de la Nueva España, terminada en 1604 y publicada en edición paleográfica por Ágreda y Sánchez (1902). En cuanto a la fecha de composición, debe aceptarse como terminus post quem, siguiendo a Castro Leal (1941: xvii) y a pesar de Amor y Vázquez (1962: 395 n. 3, 408), la publicación de la primera parte de La Araucana en 1569 - puesto que hay en el texto indicios de que Terrazas imitó el poema de Ercilla, así como el de Zapata (v. s. nn. 16 y 25; Río Torres-Murciano, 2016: $91 \mathrm{nn} .23$ y 25) - y como terminus ante quem la muerte del autor novohispano, acaecida hacia 1580 según las pruebas documentales encontradas en el Archivo General de Indias por Baudot (1988: 1086). El texto se cita por la edición de Castro Leal (1941), con referencia a número de fragmento y de verso.

${ }^{61}$ La breve referencia a la Providencia divina que a propósito de la hazaña de Francisco de Morla, que se lanza al mar a recuperar el timón de su nave, se encuentra en Gómara ("quiso Dios...”; cap. 10, Miralles Ostos, 1988: 20) da pie a que en Terrazas este capitán se represente el episodio que protagoniza como un enfrentamiento entre las "cuadrillas del infierno" acaudilladas por Neptuno y "el Dios de las alturas sempiterno" que a su juicio lo asiste (12.14-32). Y el narrador, que apostrofa a Valdivia, sacrificado por el cacique maya Canetabo, como a un mártir (15.1618), atribuye a inspiración divina el hundimiento de las naves por industria de Cortés (18), a quien Dios, cuyas "sendas" son "secretas" (10), ha encomendado la conversión de los indios (8).

${ }^{62}$ En la idea de que Aguilar rendirá como intérprete a Cortés un servicio similar al rendido por Aarón a Moiseœ (15.13-16; 16). Ya en la Carta de Veracruz se afirma que los españoles habían tenido el hallazgo de Aguilar en Yucatán "por muy gran misterio, milagro de Dios" (Delgado Gómez, 1993: 124), elucidación de la cual se hace eco Gómara al relatar el caso ("y certísimo les pareció ser milagro", cap. 12, Miralles Ostos, 1988: 24).

${ }^{63}$ La opinión acerca del encuentro con Jerónimo de Aguilar mencionada en la nota anterior es tan sólo la primera de una serie de atribuciones de causalidad divina a algunos hechos concretos de la conquista (p. ej. Delgado Gómez, 1993: 260-261, 326-327), mediante las cuales Cortés va sustentando sutilmente, sin apelar a los milagros ni apariciones relatados por los cronistas a partir de Gómara, la naturaleza providencial de su misión (Delgado Gómez, 1993: 23-27).

${ }^{64} \mathrm{El}$ énfasis salta a la vista desde la dedicatoria de la crónica a Carlos V, en la que afirma Gómara que "la mayor cosa después de la creación del mundo, sacando la encarnación y muerte del que lo crió, es el descubrimiento de las Indias", que "quiso Dios descobrir las Indias en vuestro tiempo y a vuestros vasallos, para que las convirtiésedes a su santa ley, como dicen muchos hombres sabios y cristianos" y que "comenzaron las conquistas de indios acabada la de moros, porque siempre guerreasen españoles contra infieles" (Miralles Ostos, 1988: 4). La milagrosa in- 
en un apóstrofe dirigido al mismísimo Jesucristo, la causa de los españoles es la causa de Dios ("pues es la causa vuestra de que trato", $C V$ 6.52.8), y otra dramatizar dicha idea mediante una sucesión continuada de intervenciones sobrenaturales que favorezcan $u$ obstaculicen el desarrollo de la acción épica de una manera análoga a como lo hacían en la epopeya antigua las facciones del aparato divino pagano. Ni en Zapata ni en los fragmentos conservados de Terrazas se ha desarrollado esta posibilidad narrativa, más allá de la incorporación por parte del primero de los milagros ocasionales tomados de Gómara ${ }^{65}$. Y otro tanto ocurre en la Araucana y en los diez primeros cantos del Cortés valeroso, obras ambas en las que se refiere un único hecho milagroso - las apariciones sucesivas del demonio Eponamón y de la Virgen en La Imperial (Ar. 9.10-17) y la de Santiago en Cintla ( $C V$ 5.90-92; 6.1-14), respectivamente- poniendo por garantía de veracidad el testimonio de los testigos presenciales ( $C V$ 6.5556; Ar. 9.18-21). Bien diverso es el modo en que Gabriel Lobo le presenta al lector en el canto 12 las dos intervenciones infernales que hemos estudiado; no son estas acaecimientos más o menos extraordinarios que los mortales envueltos en ellos interpretan como signos de la acción de la Providencia, sino actuaciones muy concretas llevadas a cabo por personajes no humanos con la intención de influir en el comportamiento de los personajes humanos, y garantizadas en cuanto a su autenticidad por la ominisciencia del narrador épico.

La apreciación de esta diferencia exige que, lejos de limitarnos a medir la mayor o menor cabida que se concede en cada poema a lo maravilloso en sentido lato, tratemos de esclarecer la posición adoptada por cada poeta frente a las respuestas que a la cuestión de la maquinaria sobrenatural ofrecían los distintos modelos. Ercilla la suprime de manera similar a como la había suprimido Lucano, aunque reservándole la responsabilidad última en el desarrollo de la acción a un Dios que, con la excepción de la aparición de la Virgen en La Imperial, no interviene directamente en la narración ni por sí mismo ni a través

tervención del apóstol Santiago en la batalla de Cintla, en la cual el matamoros de Clavijo, identificado con el misterioso "hombre en un caballo rucio picado" mencionado en la Relación de Andrés de Tapia (García Icazbalceta, 1866: 559-560), deviene mataindios (cap. 20, Miralles Ostos, 1988: 34-35), es el primero de los portentos en el orden de la narración de Gómara, aunque no en el cronológico, pues ya antes de la llegada de los españoles hubo en México señales sobrenaturales, como las hubo después durante el cerco de la ciudad (v. i. n. 65).

${ }^{65}$ Entre los presagios que precedieron la conquista, el ya mencionado del cautivo consolado por un mensajero celeste lo narra Zapata (14.124-126), al igual que Gómara (cap. 145, Miralles Ostos, 1988: 207-208), tras el de las extrañas luces que se dejaban ver por oriente y el de los hombres armados que peleaban por el aire, y antes del terremoto de 1520 -al que se refiere el épico (14.126.8) con expresión idéntica a la del cronista ("reventó la tierra", Miralles Ostos, 1988: 208) - . Incluye asimismo Zapata en su relato la aparición de Santiago en Cintla (12.106; 13.21-24) y la ayuda prestada a los españoles por este y por la Virgen durante el asedio de México (14.76-80), que se hallaba igualmente en Gómara (cap. 105, Miralles Ostos, 1988: 148-149). 
de sus ministros ${ }^{66}$. Camões la conserva con la misma forma y la misma función narrativa - favorecer u obstaculizar la acción heroica - que tenía en Virgilio, pero dotándola de sentido nuevo: si Virgilio le había infundido sentido romano al aparato divino heredado de Homero convirtiendo en valedor del destino imperial de los Enéadas a un Júpiter identificado con el hado, Camões le infunde sentido cristiano al aparato divino heredado de Virgilio convirtiendo en valedor de la misión evangelizadora de los Lusíadas a un Júpiter identificado con la Providencia (Lus. 10.83). Mas esta vinculación del Júpiter virgiliano al Dios cristiano, que había sido intentada sin demasiada consistencia por Petrarca en un solo pasaje de su África (7.661-725), y que en el propio Camões entraña incoherencias ${ }^{67}$, no dejaba de resultar problemática. Ya antes de que la Inquisición portuguesa tomara cartas en el asunto ${ }^{68}$, Erasmo de Rotterdam había reprobado ásperamente en su Ciceroniano (Gambaro, 1965: 278-280) la contaminación de lo cristiano con lo pagano en el De partu virginis (1526) de Jacopo Sannazaro, epopeya de asunto bíblico en la cual, aun sin que se llegue a constitur un aparato divino plenamente estructurado, se da entrada a las ninfas del río Jordán y a las profecías del dios marino Proteo (3.281-488). Pero será Tasso (1587: 3r-4r) quien, tras condenar el recurso a los dioses de la Antigüedad como una falta contra la verosimilitud, proponga la alternativa:

$\mathrm{O}$ vogliamo ricorrer talora alle deità, che da'gentili erano adorate, o non vogliamo ricorrervi; se non vi ricorriamo mai, viene a mancarvi il meraviglioso; se vi ricorriamo, resta privo il poema in quella parte del verisimile [...]. Attribuisca il poeta alcune operazioni, che di gran lunga eccedono il poter degli uomini, a Dio, agli Angioli suoi, a'Demoni, o a coloro a'quali da Dio, da'Demoni è concessa questa podestà, quali sono i Santi, i Maghi, le Fate.

Esta opción, formulada así en el primero de los Discorsi dell'arte poetica, compuestos en los años 60 pero no publicados hasta 1587, es, por supuesto, la

\footnotetext{
${ }^{66}$ Recuérdese que ya Lucano, a pesar de su negación expresa de la intervención divina en los asuntos humanos (v. s. n. 7), había hecho coincidir el resultado último de la guerra civil con la voluntad de los dioses en un famoso pasaje de la Farsalia cuyo tono de reproche es, naturalmente, inconcebible en un poeta cristiano ("victrix causa deis placuit, sed victa Catoni", 1.128).

${ }^{67}$ Extraña, en efecto, que Camões, contradiciendo la tradición patrística que identificaba a los dioses paganos con los demonios, los equipare a los ángeles servidores de Dios (10.84), después de haber reservado la primera interpretación para Baco (8.46-50), quien, siendo demonio, se relaciona con los númenes celestes con la misma familiaridad con que lo hacía en la epopeya antigua un olímpico con sus pares. Alves (2001: 611-616) entiende que debió de resultar, sin embargo, hasta cierto punto admisible la identificación de Júpiter con la Providencia divina y no con el mismísimo Dios, considerado irrepresentable por el poeta (Lus. 10.80-81).

${ }^{68}$ Las dos estrofas de los Lusíadas (10.83-84) en las que se identifica expresamente a Júpiter con la Providencia y a los otros dioses con los ángeles fueron suprimidas en la edición censurada de 1584, que, desde la sustitución de "deoses" por "ídolos" (1.23.3), desmantela torpemente la alegoría del aparato pagano propuesta por Camões.
} 
que pone en práctica el épico italiano en la Jerusalén liberada, que debió de venir a manos de Gabriel Lobo Lasso cuando el Cortés valeroso se hallaba en un avanzado estado de redacción ${ }^{69}$. Esto explicaría por qué nuestro autor, tras haber escrito diez cantos a la manera de Ercilla y haber jugado en el undécimo con la manera de Camões, introdujo en el duodécimo dos intervenciones infernales que apuntan ya claramente a la manera de Tasso ${ }^{70}$. De que el resultado de este último ensayo lo satisfizo da prueba el papel que la maquinaria dualista cristiana desempeña en la versión corregida y aumentada de la epopeya de Hernán Cortés que, bajo el título simplificado de Mexicana, publicó en 1594, dos años antes de que las ideas de Tasso acerca de la verosimilitud de la religión fueran propuestas al público español por Alonso López Pinciano (1596: 197-198) ${ }^{71}$.

\section{LA MEXICANA}

\subsection{El paradigma tassesco}

La Primera parte del Cortés valeroso y Mexicana se interrumpe abruptamente al llegar a la descripción de la inquietud de los españoles, a cuya ansiedad por el cambio de actitud de Moctezuma ha venido a sumarse la noticia del desembarco de Narváez (12.126-130). Mas la promesa de una segunda parte, explicitada en los dos versos finales ("mas quien desto el suceso ver desea, me aguarde, y la segunda parte lea", 12.130.7-8), no llegó a cumplirse tal como el precedente de la Araucana y las palabras dirigidas por el propio Lasso a don

\footnotetext{
${ }^{69}$ Puesto que la primera edición de la Liberada autorizada por Tasso, impresa en Ferrara por Vittorio Baldini, está fechada el 24 de junio de 1581 y la aprobación del poema de Lasso el 8 de marzo de 1584, este pudo acceder en algún momento entre ambas fechas al texto italiano de la epopeya de aquel, cuya primera traducción española, la de Juan Sedeño, data de 1587 (v. Arce, 1973: 36).

${ }^{70}$ El modelo mitológico camoeniano, seguido regularmente por la épica portuguesa del XVI, entre cuyos poetas destaca Jerónimo Corte Real, resultó, así pues, desplazado en España por un tassismo que, ya en el siglo siguiente, llegó a abrirse paso también en el país vecino (Alves, 2001: 328, 573), y que debió encontrar en el nuestro el campo abonado por el rechazo a los dioses paganos que estaba ya expreso en una epopeya tan temprana como la primera parte de la Carolea de Jerónimo Sempere, publicada en 1560 ("no llevo cuenta alguna con el Marte, / con Júpiter, Tritonia y ficto Divo", 1.2.2-3), y que apenas dejó lugar para excepciones como la constituida por el Libro de los hechos del muy valeroso caballero don Álvaro de Bazán, de Baltasar del Hierro (1561). Alves (2001: 555-556, 617, 671) ha hecho ver muy bien cómo, en el siglo XVII, las críticas al aparato divino de Camões, y aun algunas de las defensas que de él se hacen, como la de Faria y Sousa (1639: III, col. 78D), están determinadas ya por la asimilación de la preceptiva tassesca.

71 De un Alonso López identificable con el Pinciano es uno de los sonetos en alabanza de Cortés incluidos por Lasso en sus Elogios (1601: 66r), como bien notó Amor y Vázquez (1967: 187; 1970: li n. 30).
} 
Fernando Cortés lo habrían hecho prever ${ }^{72}$. A pesar de que avanza en el relato de la conquista hasta abarcar la batalla de Otumba y la retirada de los de Cortés a Tlaxcala, la Mexicana de 1594 es, según se reconoce en su portada, una versión de la epopeya de 1588 “emendada y añadida por su mismo autor”. Está dividida en veinticinco cantos, sin que ello quiera decir que sea nuevo todo lo que se encuentra en los trece añadidos a los doce del Cortés valeroso ${ }^{73}$, y lleva una aprobación sin fecha firmada por don Alonso de Ercilla, así como un prólogo del licenciado Jerónimo Ramírez, secretario de don Fernando Cortés, cuya principal función consiste en justificar la salida a la luz de esta segunda edición de la epopeya de Gabriel Lobo Lasso, así como la presencia en ella de nuevas ficciones (Amor y Vázquez, 1970: 9-10) ${ }^{74}$ :

Van en convenientes lugares algunas ficciones ingeniosas, sin las cuales pierden el ser y gusto las obras de poesía. No quiso antes usar de ellas el autor por parecerle que de esta manera guardaría mejor el rigor que pide la historia; después acá, considerando de la importancia que es (mayormente a los que escriben metro) juntar lo dulce con lo provechoso, quiso tomar la licencia que se concede al poeta para fingir.

De las dos ficciones por cuya introducción se había disculpado el propio Lasso en el prólogo del Cortés valeroso, la primera, la fiesta mitológica del canto 11, ha desaparecido de la Mexicana, aunque no sin dejar rastro $^{75}$. El concilio infernal y el envío de Tezcatlipuca a la casa de la Envidia se han conservado, en cambio, sin variaciones significativas (Mex. 21.38-66; CV 12.86-114), excep-

72 Afirma, en efecto, Lasso en la carta al nieto de Hernán Cortés fechada en 1586 e incluida entre los preliminares del Cortés valeroso: "Yo quedo prosiguiendo en la Segunda parte desta historia, como por la precedente [carta] del Marqués, padre de V. M., me es pedido" (Pullés-Linares, 2005: 123).

${ }^{73}$ Los acontecimientos narrados en los cantos 1-12 del Cortés Valeroso ocupan los cantos 121 de la Mexicana, en cuyos cuatro cantos restantes se relatan la derrota de Narváez (22), el levantamiento de los indios y el regreso a México de Cortés (23), la noche triste (24) y la batalla de Otumba y la retirada a Tlaxcala (25).

${ }^{74}$ El texto de la Mexicana se citará de ahora en adelante por la edición de Amor y Vázquez (1970), modificando en ocasiones la ortografía y la puntuación, con remisión a número de canto, de estrofa y, en su caso, de verso para el poema, y a número de página para los preliminares y las notas.

${ }^{75}$ La mayor parte de la profecía de Calianera ( $C V$ 11.60-77), sin las estrofas referidas al propio Lasso, es puesta en boca del río Tabasco (Mex. 11.11-37.4), aunque hay diferencias debidas fundamentalmente a la ubicación del vaticinio antes de la fundación de Veracruz (Mex. 11.13-17), al acentuado tono de cruzada que este comparte con el resto de la Mexicana (11.18.7-8, 36; v. Amor y Vázquez, 1970: XXXIX-XL) y a la confluencia del modelo camoeniano (Lus. 10.6-143) con el virgiliano, ya que la aparición del río mexicano a Cortés está modelada sobre la de Tiberino, el dios del Tíber, a Eneas (Aen. 8.36-65), modelo a su vez de la del Ganges y el Indo al rey don Manuel (Lus. 4.71-74); v. Amor y Vázquez (1970: 80 n. 2), Peña (1994: 291) y Marrero-Fente (2015: 278). 
tuado el hecho de que se generaliza la identificación, habitual en Tasso, del demonio con Plutón, apenas esbozada en la versión primera ${ }^{76}$. Y otro tanto sucede con la aparición de Acamapich a Moctezuma (Mex. 21.70-75; CV 12.119-124), con la salvedad de que no es ya el demonio, sino la furia Megera, quien se oculta bajo el semblante del primero para incitar al segundo a que se libre de Cortés. Ocurre, sin embargo, que, cuando estas escenas tienen lugar, ni Plutón ni Megera son personajes desconocidos para el lector de la Mexicana. Plutón ha sido presentado desde el principio (1.8 y sigs.) como antagonista infatigable de Cortés, papel que desempeña ya por sí mismo, como cuando se aparece al cacique Tabasco (5.49-62); ya mediante prodigios horrendos, como en Potonchán (6.5658); ya a través de su hermano Neptuno, que desencadena contra los españoles los peligros del mar (1.11, 27-44; 2.5 y sigs.; 5.10-17), o de Tezcatlipuca; ya mediante Megera, que siembra la discordia entre los cristianos tras el hundimiento de las naves (15.18 y sigs.) y estimula repetidamente la belicosidad de los indios contra estos (16.7 y sigs.; 19.53-54; 23.74.4; 24.54, 65). Y a las potencias del infierno se enfrenta, también desde el principio, el arcángel San Miguel, que es enviado por Dios para calmar la tempestad desatada por Neptuno (2.27 y sigs.) y apoya una y otra vez a los españoles en general y a Cortés en particular (5.34 y sigs.; 10.23; 15.62; 17. 51 y sigs.; 19.24, 50; 25.10 y sigs., 48) ${ }^{77}$. Así pues, si en el último canto del Cortés valeroso habían entrado en escena los demonios, en la Mexicana intervienen además como personajes los ángeles e incluso Dios. Por un lado, Gabriel Lobo ha creado en su segundo poema una maquinaria infernal coherente en el seno de la cual tanto los ídolos de los antiguos como los de los indios se equiparan siempre a los demonios opuestos a la evangelización de la Nueva España, con lo que ha evitado las incongruencias y extravagancias doctrinales en las que había incurrido Camões ${ }^{78}$. Por otro, ha

\footnotetext{
${ }^{76}$ Mientras que en el Cortés valeroso se denomina al demonio primeramente Lucifer (12.86.1), después Luzbel (12.103.6) y sólo al final, en el parlamento que dirige Tezcatlipuca a la Envidia, Plutón (12.106.2), en la Mexicana su identificación con el dios romano del inframundo se plantea ya en los dos primeros lugares $(21.38 .6,55.6)$, lo cual la hace innecesaria en el tercero (21.58.2).

${ }^{77}$ Intervenciones del arcángel San Gabriel en ayuda de Carlomagno y de Rodrigo Díaz de Vivar se pueden encontrar ya en el Cantar de Roldán (834, 2847-2848, 3609-3614, 3993-3998) y en el Cid (404-412) respectivamente, y a San Miguel le concede Ariosto un papel destacado en el canto 14 (75 y sigs.) del Orlando furioso; pero es Tasso quien convierte a las milicias celestiales —ya se trate de San Gabriel (GL 1.11 y sigs.) o de San Miguel (9.58 y sigs.), o de ángeles custodios (7.80) o no claramente identificados (8.84) - en contrapartida continua de las potencias del infierno. Gregory (2006: 154-156) ha llamado la atención acerca de las ventajas que esta solución presenta con respecto a la opción de Trissino, quien, en su Italia liberada de los godos (15471548) había dividido a los ángeles entre partidarios de los godos y partidarios de los bizantinos.

${ }^{78}$ Además de a Plutón y Neptuno, se menciona en la Mexicana a Apolo, el "protector de Delo" (6.53.8), para identificarlo con el dios-sol adorado por los indios. Las referencias a la identidad que se da entre los ídolos de estos y los demonios son, por lo demás, recurrentes $(2.29$; $4.14,5.58-62,25.29-30)$.
} 
opuesto a este infierno grecorromano y mexicano un cielo decididamente cristiano y favorable a la conquista, con lo que ha resuelto a la manera de Tasso la vieja cuestión de la doble causalidad épica. Como bien señaló José Amor y Vázquez (1967: 187-188 y 1970: li-liii), la operatividad en la Mexicana de la maquinaria dualista cristiana se debe, al igual que la presentación de Cortés como "general de Cristo" a la manera de Godofredo de Bouillon, a la utilización directa de la Jerusalén liberada por parte de nuestro poeta ${ }^{79}$. Bastará un ejemplo para mostrar hasta qué punto el modo en que el épico español lleva a cabo el desdoblamiento del plano sobrenatural debe al italiano no sólo el planteamiento general, sino también pasajes y verbalizaciones concretas.

En el canto 9 del Cortés valeroso, las pocas líneas dedicadas por Gómara (cap. 42, Miralles Ostos, 1988: 65) al descontento suscitado en algunos de los expedicionarios por la decisión de barrenar las naves se amplifican considerablemente. Lasso refiere prolijamente y en estilo directo la queja de un soldado anónimo (20-24) y la subsiguiente exhortación de Cortés (26-35), así como la animosa reacción de la mayoría a las palabras del capitán (36-38); no hay, empero, sino un tímido atisbo de trama sobrenatural detrás del afán de sedición, perceptible en la presencia de las furias Alecto y Tisífone, que acompañan la expansión de la discordia más como personificaciones de los afectos que difunden que como personajes perfectamente definidos (18-19). En el canto 15 de la Mexicana (18-45) el conato de revuelta es, en cambio, provocado por el diablo, que le encarga a Megera sembrar la discordia en el campo de Cortés (15.18-21) como el demonio Astarot le encarga a Alecto hacer lo propio en el campo de Godofredo $\left(G L\right.$ 8.1-8.4 ${ }^{80}$. Y la deuda con Tasso no acaba ahí, ya que el sedicioso anónimo del Cortés valeroso deviene en la Mexicana (15.22-58) Celidón, sobre el cual ejerce Megera su maligna influencia como en la Liberada (8.5775) la ejerce Alecto sobre Argilano. El modelo remoto de este tipo de escenas se encuentra, como es sabido, en las espeluzantes visitas que en el libro 7 de la Eneida hace Alecto por encargo de Juno a Amata (341-372) y a Turno (406-

${ }^{79}$ Los lugares del Cortés valeroso $(5.28 .5 ; 5.71 .1 ; 10.65 .3)$ cuya redacción ha sido modificada en la Mexicana $(10.22 .5 ; 11.52 .1 ; 18.24 .3)$ para otorgar a Cortés el título de "general de Cristo" — que cuenta en la Liberada con análogos como campione di Cristo $(5.33 .6 ; 7.34 .4 ; 18.94 .1)$ y cavalier di Cristo $(9.5 .8 ; 12.87 .2 ; 19.52 .3)$ - han sido señalados por Amor y Vázquez (1970: xxxviii n. 15), a quien ni Alves (2001: 78-80) ni Martínez (2010) ni Blanco (2013: 28-29) hacen plena justicia. Además, a los episodios ariostescos incluidos el Cortés valeroso - los dos de Clandina ( $C V$ 4.51-115; 8; Mex. 9.7-79; 14) y el de Gualca y Alvarado ( $C V$ 12.16-28; Mex. 20.18-30), acerca de los cuales v. s. nn. 15 y 16 - se ha añadido en la Mexicana el de la amazona Taxguaya y Sandoval (Mex. 18), basado en el de Clorinda y Tancredo (GL 12).

80 A la furia Megera, mencionada de paso en la Eneida (12.846), en la Farsalia (1.577; 6.730) y en la Liberada (2.91.4), se le había adjudicado un papel narrativamente importante en el libro 11 de la Tebaida de Estacio (59 y sigs., 80 y sigs., 113 y sigs., 136 y sigs., 150 y sigs.), así como en el concilio infernal de la invectiva In Rufinum de Claudiano (1.74 y sigs.). 
474). En cuanto atañe al pasaje que nos ocupa Virgilio fue, sin embargo, claramente desplazado por Tasso en la atención de Gabriel Lobo. Así lo demuestran los paralelismos estructurales y textuales ${ }^{81}$, continuados hasta que, tras haber elevado Cortés una oración (Mex. 15.46-47) no pronunciada por él ni en Gómara ni en el Cortés valeroso, pero sí por Godofredo en la Liberada (8.7677), el episodio se rubrica con una aparición angélica (Mex. 15.62) tomada asimismo del poema italiano $(G L 8.84)^{82}$. Hay, no obstante, pasajes de la Mexicana en los cuales la prelación entre los dos modelos se invierte, de tal manera que Virgilio se sobrepone a Tasso.

\subsection{El contrapunto virgiliano}

El incrementado virgilianismo de la Mexicana es, con respecto al Cortés valeroso, palpable desde el primer verso: el "canto las armas y el varón famoso" con que sustituye Lobo el "canto el furor de Marte sanguinoso" de la primera versión evoca antes el arma virumque cano de la Eneida que el "canto l'arme pietose e'l capitano" de la Liberada ${ }^{83}$.

La fidelidad a Tasso por la que el segundo proemio lassiano abandona la que Alves (2001: 79-80) ha denominado "multiplicidad ariostesca" del primero es, de hecho, menos "estricta" de lo que este estudioso ha pretendido ${ }^{84}$. Y lo mismo

${ }^{81}$ La presentación de Celidón se corresponde, en ocasiones estrofa por estrofa, con la de Argilano (Mex. 15.22-23, 25; GL 8.57-58, 59), y la visión de los sacrificios humanos de México que le presenta a aquel Megera (Mex. 15.25) reescribe la del cadáver de Reinaldo que le presenta a este Alecto (GL 8.60.1-6). Análogos paralelismos se dan entre las palabras de una y otra furia (Mex. 15.28.7-30, GL 8.60.7-62.2), entre las maneras como una y otra inspiran a sus respectivas víctimas (Mex. 15.30.7-8, GL 8.62.3-4) y entre los modos en que en uno y otro poema se relata la expansión de la sedición (Mex. 15.43, GL 8.72; Mex. 15.45.1, GL 8.71.7-8).

${ }^{82}$ No deja de ser significativo a este respecto que, en esta imitación de Tasso, Lobo haya suprimido precisamente el símil que comparaba la revuelta con una caldera desbordada por el hervor, que en el poema italiano (8.74) era marca inequívoca de filiación virgiliana (Aen. 7.462-465).

${ }^{83}$ Tanto Tasso como Lasso añaden un adjetivo que no se encuentra en Virgilio, pero, mientras que el italiano se lo adjudica al primero de los sustantivos ("arme pietose"), el español se lo adjudica al segundo ("varón famoso"), como antes había hecho Hernández de Velasco ("las armas y el varón ilustre canto", 1555: 1r) y Camões ("as armas e os barões assinalados", Lus. 1.1). La Eneida se citará en lo sucesivo por la versión de Velasco, ya que de la utilización de esta por parte de Lasso dan prueba numerosos paralelismos textuales como los que a continuación se verán.

${ }^{84}$ La oración subordinada de relativo, que en la Liberada se reduce a un solo verso ("che'l gran sepolcro liberò di Cristo", 1.1.2) reescribe en la Mexicana la referencia virgiliana a un viaje dispuesto por una potencia superior ("por disposición del justo cielo", 1.1.2; "obedeciendo al invincible hado", Aen. 1.2, Hernández de Velasco, 1555: 1r), con su punto de partida ("que .../ salió de Iberia", 1.1.2-3; "huido del troyano reino", Aen. 1.1) y su punto de llegada ("arribó del Antípoda en el suelo", 1.1.4; "vino a nuestra Italia", Aen. 1.2), sin olvidar mencionar las peregrinaciones del héroe por mar y por tierra ("aquel que por por el mar tempestüoso / y varias tierras ... / ... perseguido", 1.1.5-7; “aquel que por mil mares y mil tierras / fue acá y allá rebuelto y 
puede decirse del diseño estructural y de algunos episodios de la Mexicana, en los cuales la influencia directa de Virgilio sobrepuja claramente la de Tasso.

La inequívoca filiación virgiliana de algunos episodios se deja percibir incluso en un ámbito tan tassesco como el de las apariciones angélicas. La de San Miguel a Cortés en Tabasco (Mex. 5.34-45) está modelada sobre el encuentro de Eneas con Venus en Cartago (Aen. 1.314-409) de manera muy semejante a como el motín de Celidón lo está sobre el de Argilano. En ambos pasajes se presenta inesperadamente el valedor divino en hábito de caza (Mex. 5.34; Aen. 1.314-319) ${ }^{85}$; en ambos informa a su protegido acerca del lugar en que se encuentra (Mex. 5.39-43; Aen. 1.338-368) después de que este se lo haya pedido tras haber manifestado perplejidad ante su aspecto sobrehumano (Mex. 5.36; Aen. 1.327-332); y en ambos desaparece "volviendo la cerviz rosada" y esparciendo aromas (Mex. 5.45; Aen. 1.402-404) ${ }^{86}$ después de haber animado al mortal respectivo a perseverar en su empeño (Mex. 5.44, Aen. 1.387-400).

Por encima de los episodios en mayor o menor medida tassescos o virgilianos está, sin embargo, el amplio virgilianismo estructural que determina el orden en que las dos secciones del plano sobrenatural, la infernal y la celeste, se presentan al lector de la Mexicana. En la Liberada el primero en comparecer es el mismísimo Dios, quien, tras observar desde el cielo el campamento cruzado, envía a San Gabriel a animar a Godofredo para que se apreste a tomar Jerusalén (1.7-17), mientras que la entrada en escena de Plutón se retrasa hasta el concilio del canto 4. En la Mexicana domina el canto 1 la figura de Plutón, quien, preocupado por su querida México, acude a su hermano Neptuno para que intente evitar mediante una tormenta que los españoles alcancen las costas de Yucatán, mientras que la intervención de Dios para frustrar sus planes se retrasa hasta la mitad del canto 2 (27 y sigs.). La escueta noticia de Gómara (cap. 10, Miralles Ostos, 1988: 19) acerca del temporal que dispersó la flota de Cortés antes de que arribara a Cozumel,

arrojado, Aen. 1.3), obra ahora no "de la violencia y fuerza de los dioses" (Aen. 1.4) sino "de los monstruos del reino del olvido" (1.1.8); la persecución de Cortés "por la saña vengativa / del Ángel ambicioso" (1.2.1-2) replica, igualmente, la inquina de Juno contra Eneas ("por la implacable y vengativa saña / de la servera y rigurosa Juno", Aen. 1.4), como la introducción del cristianismo en México ("hasta extirpar los ritos infernales, / del Alto introduciendo la fe viva / en los fines del suelo occidentales, / hasta dar a su cruz fijo aposento / y abatir la impiedad del viejo asiento", 1.2.4-8) replica la introducción de los dioses de Troya en el Lacio (hasta ... / ... dar a sus penates aposento en el felice Lacio", Aen. 1.5-6).

${ }^{85}$ En este caso, las palabras con que presenta Lasso la aparición ("al cual ... / visible se ofreció" 5.34.1, 5.34.4) se apegan más al original latino ("cui ... sese tulit obvia", Aen. 1.314) que las de Hernández de Velasco ("al cual ... / apareció”, 1555: 4v).

${ }^{86}$ La versión que de los versos relativos al dulce olor da Hernández de Velasco ("los sus cabellos de oro derramaron / olor divino de inmortal ambrosía", 1555: 6r) es, en este caso, más cercana al texto latino ("ambrosiaeque comae divinum vertice odorem / spiravere", Aen. 1.403404) que la variación propuesta por Lasso ("derramó la madeja destrenzada /olor por todas partes apacible", 5.45.5-6). 
recreada y amplificada sin vislumbre alguno de causalidad sobrenatural en el Cortés valeroso (2.3-14), le sirve a Lasso en la Mexicana para plantear desde el principio la dialéctica tassesca entre cielo e infierno. Pero, a la hora de proponer este enfrentamiento, el épico español no sigue la estructura narrativa de la Liberada, sino la del libro 1 de la Eneida, en el cual Juno, alarmada por los perjuicios que de la llegada de Eneas a Italia se puedan derivar para su amada Cartago, convence a Eolo para que ponga la escuadra troyana a merced de los vientos (1280). Y este paralelismo estructural se apoya en insoslayables ecos textuales. El objeto de preocupación es en ambas epopeyas una ciudad ("una ciudad famosa está asentada", Mex. 1.6.1; "una ciudad antigua fue ya un tiempo", Aen. 1.11, 1r) opulenta y belicosa ("rica, populosa, / y en ejercicio bélico estudiosa", Mex. 1.6.78; "en sumo grado rica y opulenta, / insigne en belicoso estudio y arte", Aen. 1.14), apreciada más que ninguna otra por un protector ultramundano ("de esta insigne ciudad Plutón hacía / mayor cuenta y caudal que de otra alguna”, Mex. 1.8.1-2; "de quien se dice que la diosa Juno / hizo mayor caudal que de su Samo", Aen. 1.15-16) que tiene asiento en ella ("aquí tuvo su templo suntüoso, / sus aras tintas siempre en sangre humana", Mex. 1.9.1-2; "aquí tuvo su carro, aquí sus armas", Aen. 1.16), y que desea verla engrandecida ("pretendía, / ... / hacerla de su reino la señora, / cabeza y principal legisladora", Mex. 1.8.5-8; "esta es la ciudad que ella pretendía / ... / hacer al mundo universal señora, / y de todos los reinos la cabeza", Aen. 1.16-17), a pesar de que ha oído ("bien que .... había oído", Mex. 1.10.1; "bien que había oído", Aen. 1.19-20) que alguien la ha de destruir. Y en ambos casos se reproduce en estilo directo un indignado monólogo del valedor sobrenatural que, al divisar la armada que marcha contra sus protegidos ${ }^{87}$, ve peligrar su culto si no interviene ${ }^{88}$. La imitación virgiliana no es, sin embargo, en Gabriel Lobo tan ajustada que no deje lugar para añadidos, como la conversación de Plutón con su esposa ${ }^{89}$, o para modificaciones considerables, como la que es-

\footnotetext{
${ }^{87}$ A la fidelidad al modelo virgiliano ("daban al viento alegres velas, / y del salado mar saltar hacían / blancas espumas con las naos herradas, / cuando la airada Juno..., 1.134-136, 1r) se debe, desde luego, que el relato que en el Cortés valeroso (1.51 y sigs.) partía del linaje de Cortés se inicie en la Mexicana in medias res: "Daba Cortés al favorable viento / y al mexicano golfo vela hinchada, / y las naves con presto movimiento / blanca espuma del mar alzan salada, / cuando Plutón..." (1.22.1-5).

${ }^{88}$ La sucinta pregunta de Juno (“¿será que en todo el mundo, provocado / de hoy más con tan profano y impío ejemplo, / mi honor, servicio y nombre esté olvidado / y nadie ofrezca don en mi ara o templo?", 1.48-49, 1v), que en boca del Plutón de Tasso se había dilatado a lo largo de más de dos octavas (GL 4.12.7-4.14), incorpora en la Mexicana referencias concretas a los ritos sangrientos de los indios: “¿Será que de mi culto el ejercicio / cese en el ancho imperio mexicano, / y el antiguo sangriento sacrificio, / dado con abundosa y franca mano? / ¿Será que no derrame en mi servicio / su sangre el indio, contra sí inhumano, / y será que a mis aras se les quite / la ofrenda que mi honor desacredite?" (1.25).

${ }^{89}$ Esta escena de despedida incorpora algunos elementos de los relatos poéticos acerca del rapto de Prosérpina, como la referencia a Cíane y a Aretusa (1.18.1), las ninfas que fueron testi-
} 
triba en que sea precisamente Neptuno, el dios del mar que, por iniciativa propia, pone fin a la tempestad desencadenada en la Eneida por Eolo a solicitud de Juno (1.124-156), quien la provoque, incitado por su hermano Plutón, en la Mexica$n a^{90}$. Abunda, sin embargo, en el paralelismo estructural que se da entre el comienzo de la Mexicana y el de la Eneida el hecho de que Dios ponga fin al temporal - que ha sido descrito con algunas, aunque no muchas, resonancias virgilianas $^{91}$ — mandando a San Miguel no sólo a alentar a Cortés (Mex. 2.31-36) - como alienta Mercurio a Eneas en el pasaje de Virgilio (Aen. 4.219-277) sobre el que está modelada la exhortación de San Gabriel a Godofredo ( $G L$ 1.12-17) ${ }^{92}$ sino también a preparar las tierras de occidente para el combate entre el bien y el mal que va a tener lugar en ellas (Mex. 2.37), de modo muy semejante a como Júpiter despacha a Mercurio para prepararles el terreno a los Enéadas en Cartago (Aen. 1.297-305). El heraldo divino, que en el canto 11 del Cortés valeroso (2021), a la hora de poner paz entre los españoles y los tlaxcaltecas, había mantenido el nombre y la figura del Mercurio pagano, a la manera de los dioses de los Lusíadas, los ha perdido en la Mexicana para devenir un arcángel mensajero a la manera de los de la Liberada; pero esta transformación no encubre la voz perfectamente reconocible de Virgilio, que se entrelaza con la de Tasso en armonioso contrapunto.

\section{Conclusiones}

La segunda parte de la Araucana presenta cierta inclinación a lo sobrenatural extraña a la primera, pero esta se agota en la que James Nicolopulos (2000: 65-117) ha denominado "red de profecía" relativa a la historia europea ${ }^{93}$, mien-

gos de cómo Plutón se la llevó al inframundo para convertirla en su esposa (cf. Met. 5.409-437, 465-470, 487-507; Rapt. 2.60-61, 3.295-245-253). A confusión o errata hay que atribuir el "Cicno" de Amor y Vázquez (1970: 16), puesto que en la edición príncipe (4v) se lee claramente "Ciane".

${ }^{90}$ Lasso parece haber seguido en esto a Camões, en cuyo poema (6.6 y sigs.) Baco azuza contra los portugueses a Neptuno de modo muy similar a como Bóreas, el viento del norte, instigaba a Eolo contra los argonautas en las Argonáuticas de Valerio Flaco (1.574 y sigs.).

${ }^{91}$ Inequívocamente virgilianos son la descripción de la congoja del protagonista ("sintió el pío Cortés que un frío hielo, / por sus turbados miembros se esparcía" 2.9.1-2; "cortole en aquel punto un miedo helado / los miembros turbadísimos a Eneas", Aen. 1.92, 2r) y el modo en que sus palabras se ven interrumpidas por el arreciar de la tormenta ("diciendo aquesto...", 2.15.1; "assí dicía...", Aen. 1.102, 2r).

${ }^{2}$ El Mercurio mensajero de Júpiter tomado de Virgilio había sido transformado en arcángel mensajero de Dios ya por Sannazaro (PV 1.40-154) y antes por Maffeo Vegio en su Antoníada latina (Greene, 1973: 107-112). En el ámbito de la épica hispánica, Luis Zapata, algunos de cuyos pasajes cortesianos recoge Lobo Lasso en sus Elogios (1601: 60rv-61v), había reescrito el mismo lugar del libro 4 de la Eneida para hacer a Fernando el Católico heraldo de Dios ante Carlos V (CF 7.85-87, 8.17-51; 35v-38v).

${ }^{93}$ V. s. n. 22. 
tras que la recreación épica de las guerras de Chile se sustrae al antiguo principio de la narración en doble plano que sí respetará, influido por Tasso (Arce, 1973: 41), Pedro de Oña en su Arauco domado (Lima, Antonio Ricardo, 1596). Gabriel Lobo Lasso de la Vega recorrió, en cambio, por sí mismo el camino que va de Ercilla a Tasso, o de la épica histórica privada de plano narrativo superior al dualismo teológico de la épica de cruzada. Que la Mexicana de 1594 sea una segunda versión, y no una segunda parte, del Cortés valeroso y Mexicana de 1588 se debe fundamentalmente, como advirtió Amor y Vázquez, al encuentro de Lasso con la Jerusalén liberada, cuyas consecuencias son perceptibles ya en el último canto de la primera versión. Desechado el modelo mitológico-alegórico de Camões ensayado en el penúltimo, nuestro autor aprovechó la libertad creativa en que lo había dejado en 1589 el fallecimiento de aquel enemigo de poesías y ficciones que había sido su mecenas don Martín Cortés para cantar nuevamente la conquista de México, imbricando esta vez las aventuras humanas con las maquinaciones continuas de poderosos seres sobrenaturales divididos, a la manera de Tasso, entre el bando de Dios y el bando del diablo (Amor y Vázquez, 1970: XXVII). Es, sin embargo, importante subrayar que la imitación tassesca llevó aparejada la vuelta a Virgilio, de tal manera que el archimodelo constituido por la Eneida determinó en gran medida la forma en que Lasso le propuso al lector el enfrentamiento entre cielo e infierno. Al tiempo que Tasso desplazaba a Ercilla, Virgilio desplazó a Lucano. La laboriosa confrontación de Gabriel Lobo con los diversos modelos que se le ofrecían dio, así, como resultado una maquinaria sobrenatural matizada en su evidente tassismo por un componente virgiliano no siempre achacable a la mediación de la Liberada ${ }^{94}$. Y esta doble contextura del aparato ultraterreno dejó abierta la senda que, con pocas excepciones, habría de seguir la épica cortesiana posterior $^{95}$.

${ }^{94}$ Componente que, como bien ha hecho ver Gómez Gómez (2009 y 2010), puede hallarse también en Cristóbal de Mesa, destacado cultivador de la épica de corte tassesco en España cuyo poema Las Navas de Tolosa fue publicado el mismo año que la Mexicana.

${ }^{95} \mathrm{El}$ aparato infernal o celeste-infernal tassesco-virgiliano reaparecerá, en efecto, con mayor o menor presencia en El peregrino indiano de Antonio de Saavedra Guzmán (1599), en el Canto intitulado Mercurio de Arias de Villalobos (1623), en las Cortesíadas de Juan Cortés Ossorio (ca. 1665), en la Cortesíada latina de Pedro Paradinas (ante 1691), en la Hernandía de Francisco Ruiz de León (1755), en Las naves de Cortés destruidas de Nicolás Fernández de Moratín (1785) y en la México conquistada de Juan de Escóiquiz (1789); no así en Las naves de Cortés destruidas de José María Vaca de Guzmán (1778) ni en La conquista del México por Hernán Cortés de Pedro de Montengón (1820). Las apreciaciones de Avalle-Arce (2000: 26-27, 27 n. 10) acerca de la presunta insignificancia de la influencia de Tasso en la épica de Indias son, pues, al menos por cuanto respecta al ciclo cortesiano, inexactas. 


\section{BIBLIOGRAFÍA CITADA}

Adorno, Rolena (1986): "Literary Production and Suppression: Reading and Writing about Amerindias in Colonial Spanish America", Dispositio, XI, 28-29, pp. 1-25.

Ágreda y Sánchez, José María de (1902): Baltasar Dorantes de Carranza. Sumaria relación de las cosas de la Nueva España, México, Imprenta del Museo Nacional.

Alves, Hélio J. S. (2001): Camões, Corte-Real e o sistema da epopeia quinhentista, Coimbra, Universidade de Coimbra.

Amor y Vázquez, José (1958): "Hernán Cortés en dos poemas del Siglo de Oro", Nueva Revista de Filología Hispánica, XII, pp. 369-382.

Amor y Vázquez, José (1962): "Terrazas y su Nuevo Mundo y Conquista en los albores de la mexicanidad”, Nueva Revista de Filología Hispánica, XVI, pp. 395-415.

Amor y Vázquez, José (1967): "Conquista y Contrarreforma: la Mexicana de Gabriel Lobo Lasso de la Vega", en Jaime Sánchez Romeralo y Norbert Poulussen (eds.), Actas del Segundo Congreso Internacional de Hispanistas, Nimega, Universidad de Nimega, pp. 181-191.

Amor y Vázquez, José (1970): Gabriel Lobo Lasso de la Vega. Mexicana, Madrid, Atlas.

Antonio, Nicolás (1672): Bibliotheca Hispana, I, Roma, Nicola Angelo Tinassio.

Arce, Joaquín (1973): Tasso y la poesía española, Barcelona, Planeta.

Assman, Jan (1997): Moses the Egyptian. The Memory of Egypt in Western Monotheism, Cambridge, Harvard University Press.

Aubrun, Charles V. (1956): "Poesía épica y novela: el episodio de Glaura en La Araucana de Ercilla", Revista Iberoamericana, XXI, pp. 261-273.

Avalle-Arce, Juan Bautista de (2000): La épica colonial, Pamplona, EUNSA.

Avilés Pérez, Luis (1936): Mexicana de Gabriel Lobo Lasso de la Vega, tesis doctoral, University of Illinois.

Baudot, Georges (1972): "Apariciones diabólicas en un texto náhuatl de fray Andrés de Olmos", Estudios de Cultura Náhuatl, X, pp. 349-357.

Baudot, Georges (1979): Tratado de hechicerías y sortilegios de fray Andrés de Olmos. Edición del texto náhuatl con traducción y notas en francés, México, Misión Arqueológica y Etnológica Francesa en México.

Baudot, Georges (1988): "Lupercio Leonardo de Argensola continuador de Francisco de Terrazas. Nuevos datos y documentos", Nueva Revista de Filología Hispánica, XXXVI, 1083-1091.

Blanco, Mercedes (2013): "La épica áurea como poesía", en Rodrigo Cacho Casal y Anne Holloway (eds.), Los géneros poéticos del Siglo de Oro. Centros y periferias, Woodbridge, Tamesis, pp. 13-30.

Bouterwek, Friedrich (1804): Geschichte der Poesie und Beredsamkeit seit dem Ende des dreizehnten Jahrhunderts, III, Göttingen, Johann Friedrich Röwer.

Bowra, Cecil Maurice (1945): From Virgil to Milton, London, Macmillan.

Cañizares-Esguerra, Jorge (2008): Católicos y puritanos en la colonización de América, Madrid, Marcial Pons.

Carvalho, J. Lourenço de (1970): "Camões e Valerio Flaco", Euphrosyne, IV, pp. 195-202.

Cascales, Francisco (1617): Tablas poéticas, Murcia, Luis Beros.

Castro Leal, Antonio (1941): Francisco de Terrazas. Poesías, México, Porrúa.

Cevallos, Francisco Javier (1989): "Don Alonso de Ercilla and the American Indian: History and Myth", Revista de Estudios Hispánicos, XXIII, 3, pp. 1-20.

Chevalier, Maurice (1966): L'Arioste en Espagne (1530-1650), Bordeaux, Institut d'Études Ibériques et Ibéro-Américaines de l'Université de Bordeaux.

Concha, Jaime (1969): "El otro Nuevo Mundo", en Jaime Concha, Dieter Janik, Marcelo Coddou y Luis Muñoz González, Homenaje a Ercilla, Concepción, Universidad de Concepción, pp. 31-82. 
Conti, Natale (1568): Mythologiae sive explicationum fabularum libri decem, Venetia, [Al segno della Fontana].

Cristóbal, Vicente (1988): “Tempestades épicas”, Cuadernos de Investigación Filológica, XIV, pp. $125-148$.

Cristóbal, Vicente (1995): "De la Eneida a la Araucana", Cuadernos de Filología Clásica. Estudios Latinos, IX, pp. 67-101.

Davies, Gareth A. (1979): "El incontrastable y duro hado. La Araucana en el espejo de Lucano", en Emilio Orozco Díaz, Antonio Gallego Morell, Andrés Soria Olmedo y Nicolás Marín López (eds.), Estudios sobre literatura y arte dedicados al profesor Emilio Orozco Díaz, I, Granada, Universidad de Granada, pp. 405-417.

Davis, Elizabeth B. (2000): Myth and Identity in the Epic of Imperial Spain, Columbia, University of Missouri Press.

Davis, Elizabeth B. (2002): "La épica novohispana y la ideología imperial", en Raquel ChangRodríguez (ed.), Historia de la literatura mexicana desde sus orígenes hasta nuestros días, II, México, Siglo XXI/UNAM, pp.129-152.

Delgado Gómez, Ángel (1993): Hernán Cortés. Cartas de relación, Madrid, Castalia.

Ducamin, Jean (1900): L'Araucana, poème épique par Don Alonso de Ercilla y Zúñiga. Morceaux choisis précédes d'une étude biographique et littéraire, suivis de notes grammaticales et de versification et de deux lexiques, Paris, Garnier Frères.

Everson, Jane E. (2001): The Italian Romance Epic in the Age of Humanism. The Matter of Italy and the World of Rome, Oxford, Oxford University Press.

Faria y Sousa, Manuel de (1639): Lusíadas de Luis de Camoens, Madrid, Juan Sánchez.

Fornell Lombardo, José María (1992): P. Ioseph de Anchieta. De gestis Mendi de Saa. (Poema epicum), Granada, Santa Rita.

Franco Carcedo, María Elena (1994): "La personalidad literaria de Gabriel Lobo Lasso de la Vega (1555-1615), con la edición de los Elogios y las Tragedias", tesis doctoral, Universidad Complutense de Madrid.

Gambaro, Angiolo (1965): Erasmo da Rotterdam. Il Ciceroniano, o dello stile migliore, Brescia, Scuola.

García Icazbalceta, Joaquín (1866): Colección de documentos para la historia de México, II, México, Antigua Librería.

García Icazbalceta, Joaquín (1884): "Francisco de Terrazas y otros poetas del siglo XVI", Memorias de la Academia Mexicana, II, pp. 357-425.

Gaylord, Mary Malcolm (2000): "Jerónimo de Aguilar y la alteración de la lengua (la Mexicana de Gabriel Lobo Lasso de la Vega)", en José Antonio Mazzotti (ed.), Agencias criollas. La ambigüedad "colonial" en las letras hispanoamericanas, Pittsburgh, Instituto Internacional de Literatura Iberoamericana, pp. 73-97.

Gómez Gómez, Juan María (2009): "La imitación virgiliana en Las Navas de Tolosa. Poema heroico de Cristóbal de Mesa”, en César Chaparro Gómez, Manuel Mañas Núñez y Delfín Ortega Sánchez (eds.), Nulla dies sine linea. Humanistas extremeños: de la fama al olvido, Cáceres, Universidad de Extremadura, pp. 115-129.

Gómez Gómez, Juan María (2010): "La descripción del escudo de Eneas y las historias de Orfeo y Eurídice y de Venus y Adonis en las écfrasis de Las Navas de Tolosa de Cristóbal de Mesa", en Jesús Luque, M. ${ }^{a}$ Dolores Rincón e Isabel Velázquez (eds.), Dulces Camenae. Poética y poesía latinas, Granada, Universidad de Granada, pp. 955-968.

Greene, Thomas M. (1963): The Descent from Heaven. A Study in Epic Continuity, New Haven, Yale University Press.

Gregory, Tobias (2006): From Many Gods to One. Divine Action in Renaissance Epic, Chicago, The University of Chicago Press.

Hernández de Velasco, Gregorio (1555): Los doce libros de la Eneida de Vergilio, Toledo, Juan de Ayala. 
Janik, Dieter (1969): “Ercilla, lector de Lucano", en Jaime Concha, Dieter Janik, Marcelo Coddou y Luis Muñoz González, Homenaje a Ercilla, Concepción, Universidad de Concepción, pp. 83-109.

Kallendorf, Craig (1989): In Praise of Aeneas. Virgil and Epideictic Rhetoric in the Early Italian Renaissance, Hannover/London, University Press of New England.

Kallendorf, Craig (2003): "Representing the Other: Ercilla's La Araucana and Virgil's Aeneid, and the New World Encounter", Comparative Literary Studies, XL, pp. 394-414.

Lagos, Ramona (1981): "El incumplimiento de la programación épica en la Araucana", Cuadernos Americanos, XL, 5, pp. 157-191.

Lara Garrido, José (1999): Los mejores plectros. Teoría y práctica de la épica culta en el Siglo de Oro, Málaga, Universidad de Málaga.

Lerner, Isaías (1994): "Ercilla y Lucano", en Francis Cerdan (ed.), Hommage à Robert Jammes, II, Toulouse, Presses Universitaires du Mirail, pp. 683-691.

Lerner, Isaías (1998): Alonso de Ercilla. La Araucana, 2. ${ }^{a}$ ed., Madrid, Cátedra.

Lerner, Isaías (1999): "Felipe II y Alonso de Ercilla", Edad de Oro, XVIII, pp. 87-101.

Lobo Lasso de la Vega, Gabriel (1601): Elogios en loor de los tres famosos varones Don Jaime, Rey de Aragón, Don Fernando Cortés, Marqués del Valle, y Don Álvaro de Bazan, Marqués de Santa Cruz, Zaragoza, Alonso Rodríguez.

López Pinciano, Alonso (1596): Philosophía antigua poética, Madrid, Thomás Iunti.

López Silva, Xosé Antonio (2013): "Feijoo contra los virgilianistas. La polémica sobre Lucano en el XVIII español”, en Francisco García Jurado, Ramiro González Delgado y Marta González González (eds.), La historia de la Literatura Grecolatina en España: de la Ilustración al Liberalismo (1778-1850), Málaga, Universidad de Málaga, pp. 375-394.

López Silva, Xosé Antonio (2015): "Épica latina y siglo XVIII español: Cortés, Feijoo (y la consideración de Lucano) en la ilustración española temprana", en Jesús de la Villa Polo, Patricia Cañizares Ferriz, Emma Falque Rey, José Francisco González Castro y Jaime Siles Ruiz, Ianua Classicorum. Temas y formas del Mundo Clásico, vol. III, Madrid, Sociedad Española de Estudios Clásicos, 397-404.

Marrero-Fente, Raúl (2015): "La tradición clásica en la Primera parte del Cortés valeroso y Mexicana de Gabriel Lobo Lasso de la Vega", en Bernat Garí y Christian Snoey (eds.), Clásicos para un Nuevo Mundo. Estudios sobre la tradición clásica en la América de los siglos XVI y XVII, Barcelona, Universidad Autónoma de Barcelona, pp. 277-290.

Marrero-Fente, Raúl (2017): Poesía épica colonial del siglo XVI. Historia, teoría y práctica, Madrid/Frankfurt, Universidad de Navarra/Iberoamericana/Vervuert.

Martínez, Jaime J. (2010), "La evolución del canon épico en Mexicana de Gabriel Lobo Lasso de la Vega", Edad de Oro, XXIX, pp. 169-183.

McManamon, James Edward (1955), "Echoes of Virgil and Lucan in the Araucana", tesis doctoral, University of Illinois.

Medina, José Toribio (1916): El primer poema que trata del descubrimiento del Nuevo Mundo. Reimpresión de la parte correspondiente del Carlo famoso de D. Luis Zapata, con un breve prólogo biográfico y cien compendiosas notas crítico históricas, Santiago de Chile, Imprenta Universitaria.

Menéndez Pelayo, Marcelino (1884): Historia de las ideas estéticas en España, II, Madrid, A. Pérez Dubrull.

Menéndez Pelayo, Marcelino (1911): Historia de la poesía hispano-americana, I, Madrid, Victoriano Suárez.

Menéndez Pidal, Ramón (1949): "Poesía e historia en el Mío Cid. El problema de la épica española", Nueva Revista de Filología Hispánica, III, pp. 113-129.

Milá y Fontanals, Manuel (1844): Compendio del arte poética, Barcelona, De Grau.

Miralles Ostos, Juan (1988): Francisco López de Gómara. Historia de la conquista de México, México, Porrúa. 
Moore, Olin H. (1918): "The Infernal Council”, Modern Philology, XVI, pp. 169-193.

Newman, John Kevin (1986): The Classical Epic Tradition, Madison, The University of Wisconsin Press.

Nicolas, Alexandre (1869): L'Araucana, poëme épique espagnol para don Alonso de Ercilla y Zúñiga, traduit complétement pour la première fois en français, I, Paris, Delagrave et Cie.

Nicolopulos, James (2000): The Poetics of Empire in the Indies. Prophecy and Imitation in La Araucana and Os Lusíadas, University Park, The Pennsylvania State University Press.

Peña, Margarita (1994): "La poesía épica en la Nueva España (siglos XVI, XVII y XVIII)", en Julio Ortega y José Amor y Vázquez (eds.), Conquista y contraconquista. La escritura del Nuevo Mundo, Providence/México, Brown University/El Colegio de México, pp. 289-301.

Pierce, Frank (1961): La poesía épica del Siglo de Oro, Madrid, Gredos.

Post, H. Houwens (1958): A Little Known Source of the Lusiads, Groningen, Wolters.

Puibusque, Adolphe de (1843): Histoire comparée des littératures espagnole et française, Paris, Dentu.

Pullés-Linares, Nidia (2005): Gabriel Lobo Lasso de la Vega. De Cortés valeroso y Mexicana, Frankfurt/Madrid, Vervuert/Iberoamericana.

Quint, David (1993): Epic and Empire. Politics and Generic Form from Virgil to Milton, Princeton, Princeton University Press.

Quintana, Manuel José (1833): Poesías selectas castellanas. Segunda Parte. Musa épica, o colección de los trozos mejores de nuestros poemas heroicos, I, Madrid, D. M. de Burgos.

Rajna, Pio (1900): Le fonti dell'Orlando furioso, 2. ${ }^{\text {a }}$ ed., Firenze, Sansoni.

Reifferscheid, August (1860): C. Suetoni Tranquilli praeter Caesarum libros reliquiae, Leipzig, Teubner.

Reynolds, Winston A. y José Toribio Medina (eds.) (1984): El primer poema que trata del descubrimiento y conquista del Nuevo Mundo, reimpresión de las partes correspondientes del Carlo famoso de Luis Zapata, José Porrúa Turanzas.

Río Torres-Murciano, Antonio (2016): "Polifemo en Yucatán. Variaciones sobre un episodio de la Eneida en la épica cortesiana del del Quinientos", Cuadernos de Filología Clásica. Estudios Latinos, XXXVI, 1, pp. 85-105

Romano Martín, Sandra (2017): "Nuevo Mundo y Conquista de Francisco de Terrazas y la tradición virgiliana", Bulletin of Spanish Studies, 94, 6, pp. 625-655.

Rosell, Cayetano (1851): Poemas épicos, I, Madrid, Rivadeneyra.

Royer, Alphonse (1879): Étude littéraire sur l'Araucana d'Ercilla, Dijon, Darantière.

Rufo, Juan (1584): La Austríada, Madrid, Alfonso Gómez.

Salgado, Antonio (1950): "Os Lusíadas e o tema das Argonáuticas", Ocidente, XXXVIII, pp. 277-294.

Salgado, Antonio (1951): "Os Lusíadas e o tema das Argonáuticas”, Ocidente, XL, pp. 261-284.

Sánchez Quirós, Javier (2010): Julio César Stella. La Columbeida, Alcañiz/Madrid, Instituto de Estudios Humanísticos/CSIC.

Schlegel, Friedrich (1815): Geschichte der alten und neuen Litteratur, II, Wien, Karl Schaumburg und Compagnie.

Schuessler, Michael K. (1997): “Los trabajos de Persiles y Sigismunda: ¿Historia occidental?”, Mester, XXVI, pp. 17-42.

Schwartz Lerner, Lía (1972): “Tradición literaria y heroínas indias en La Araucana”, Revista Iberoamericana, XXXVIII, pp. 615-625.

Tasso, Torquato (1587): Discorsi dell arte poetica, et in particolare del poema eroico, Ferrara, Giulio Vassalini.

Tasso, Torquato (1824): Discorsi del poema eroico, Milano, Classici Italiani.

Ticknor, George (1864): History of Spanish Literature, II, 3. ${ }^{\mathrm{a}}$ ed., Boston, Ticknor and Fields. 
Vega, María José (2010): “Idea de la épica en la España del Quinientos”, en María José Vega y Lara Vilà (eds.), La teoría de la épica en el siglo XVI (España, Francia, Italia y Portugal), Vigo, Academia del Hispanismo, pp. 103-135.

Vilà, Lara (2003): "La épica española del Renacimiento (1540-1605): propuestas para una revisión", Boletín de la Real Academia Española, LXXXIII, pp. 137-150.

Vilà, Lara (2006): "Épica, historia y la construcción de los mitos nacionales. La problemática de la teoría y la praxis de la épica culta en el siglo XVI (en Italia y España)", História e perspectivas, XXXIV, pp. 86-106.

Vilà, Lara (2009): Luis Zapata de Chaves. Carlo famoso, Bellaterra, Universidad Autónoma de Barcelona.

Vilà, Lara (2010): "Fama y verdad en la épica quinientista española. El virgilianismo político y la tradición castellana del siglo XV", Studia Aurea, IV, pp. 1-35.

Vilà, Lara (2011): "Vera cum fíctis. L'allégorie historique selon Servius et l'idée de l'epos", en Monique Bouquet y Bruno Méniel (eds.), Servius et sa réception de l'Antiquité à la Renaissance, Rennes, Presses Universitaires de Rennes, pp. 145-160.

Virués, Cristóbal de (1587): El Monserrate, Madrid, Querino Gerardo.

Weiner, Jack. (2005): Cuatro ensayos sobre Gabriel Lobo Lasso de la Vega, Valencia, Universidad de Valencia.

Wogan, Daniel (1941), "Ercilla y la poesía mexicana", Revista Iberoamericana, III, pp. 371-379.

Wolffhart, Conrad (1581): Officina Ioannis Ravisii Textoris Nivernensis, Basileae, Brylinger.

Fecha de recepción: 18 de noviembre de 2016

Fecha de aceptación: 25 de enero de 2017 